\title{
CREATING THE LABORATORY'S FUTURE
}

A Strategy for Lawrence Livermore National Laboratory
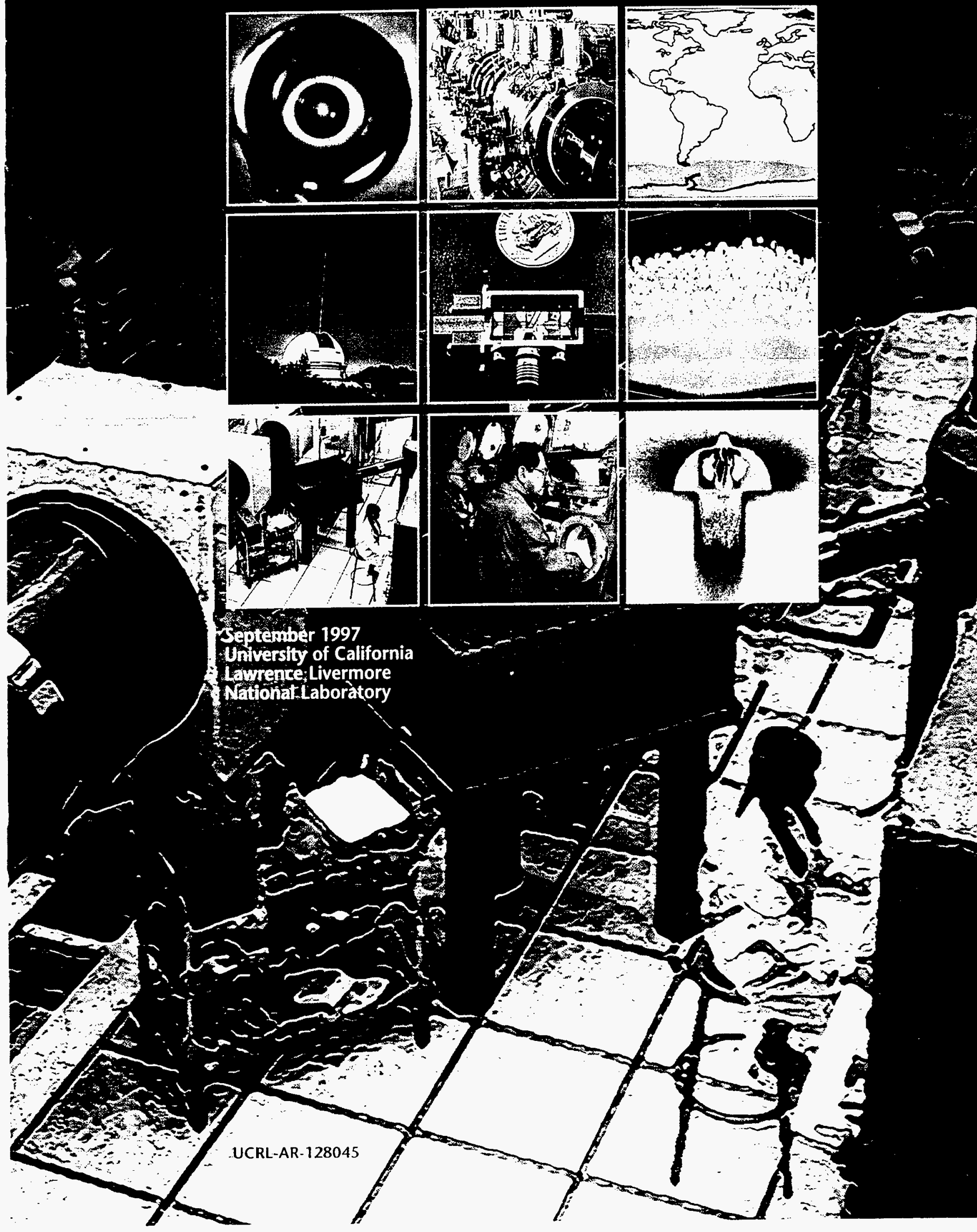


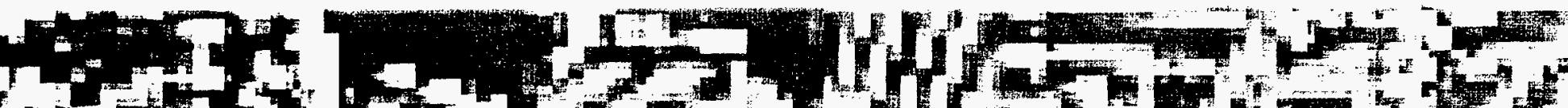

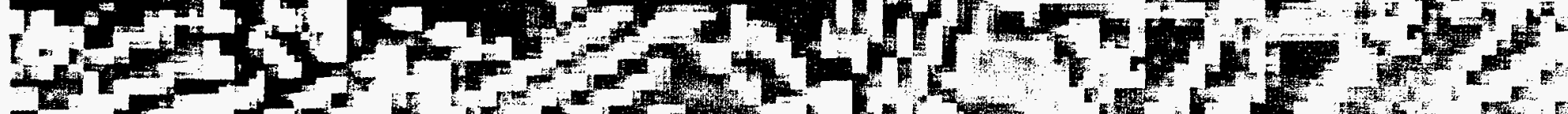

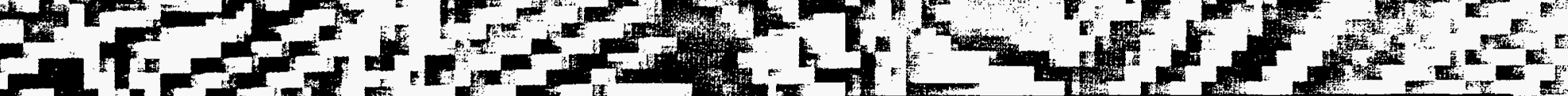
T.

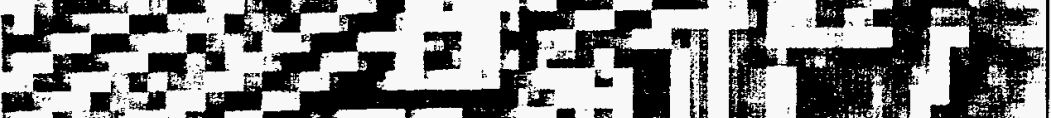

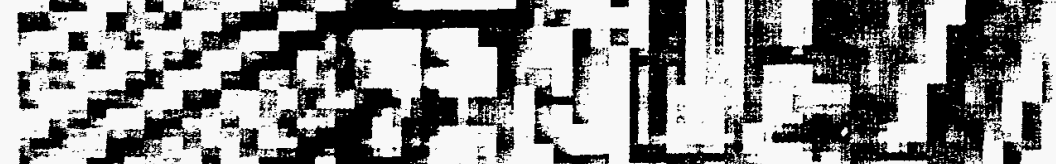

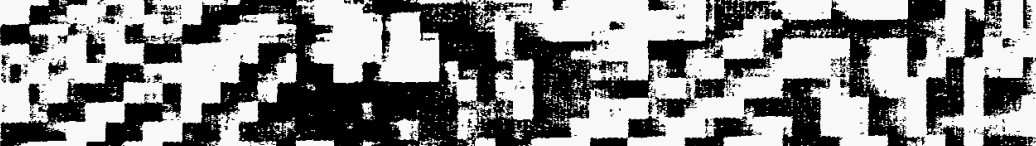

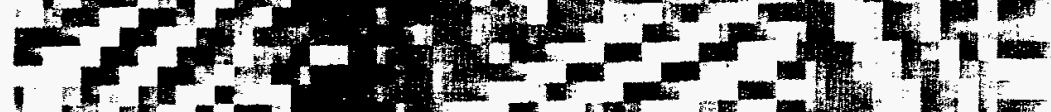

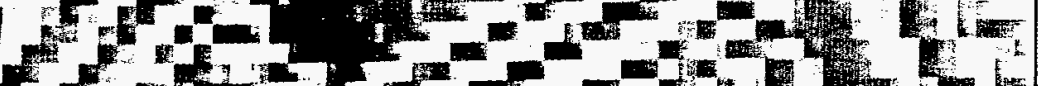
(n) Fer

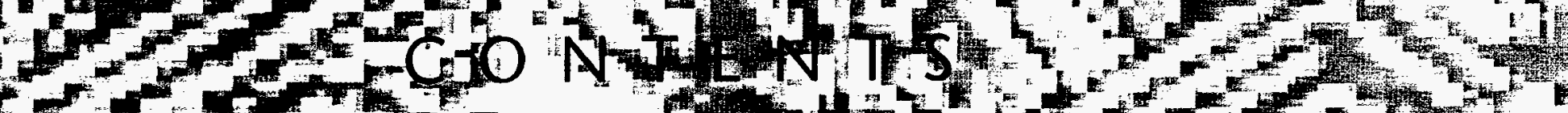

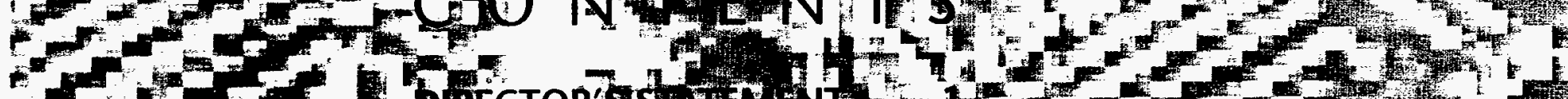

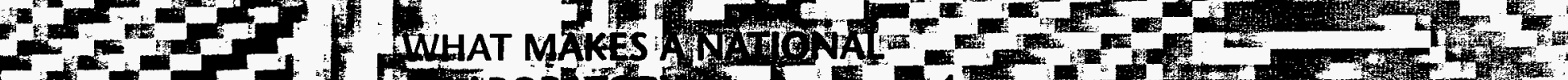

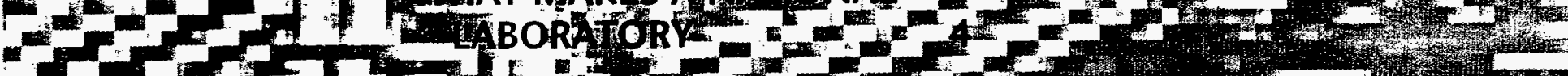

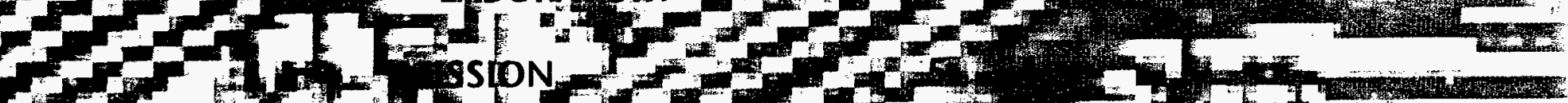

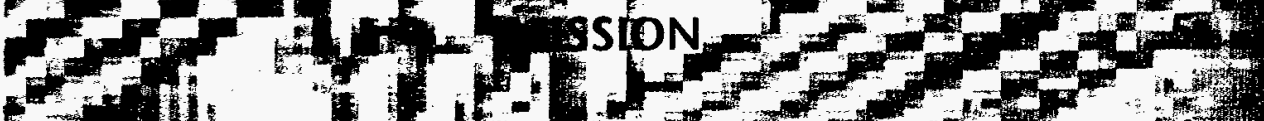

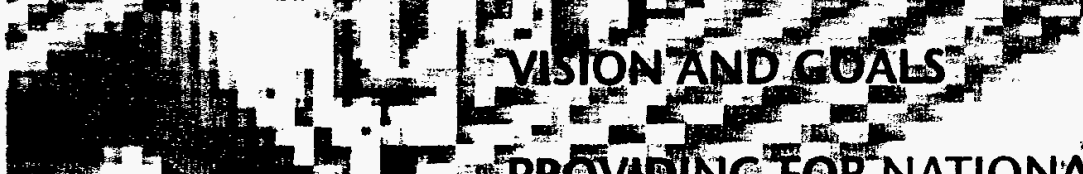

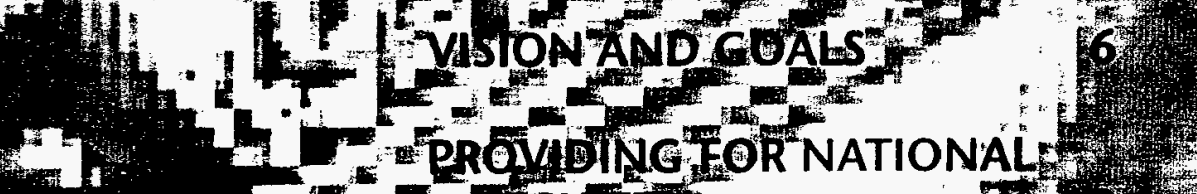

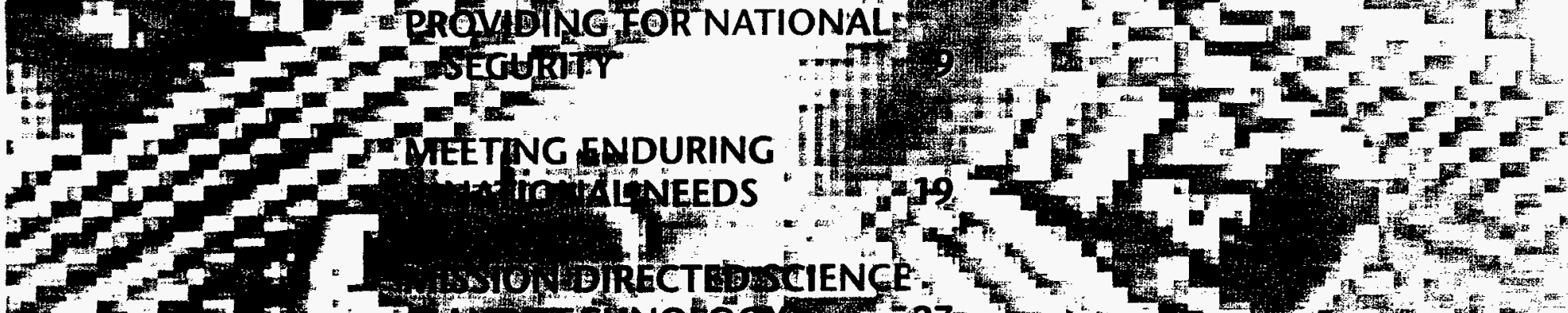
W

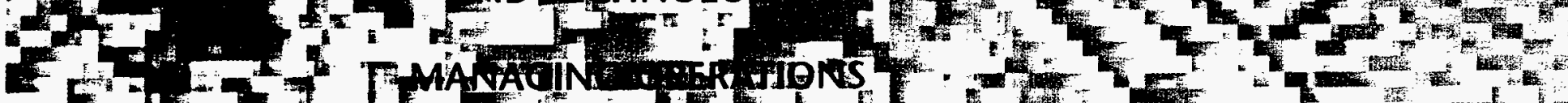

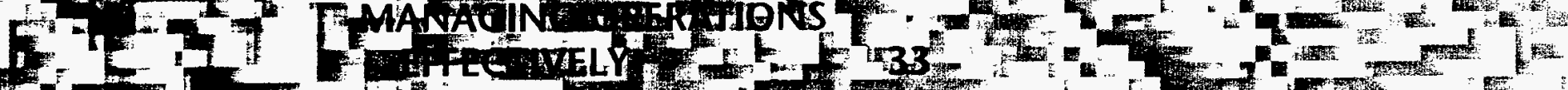

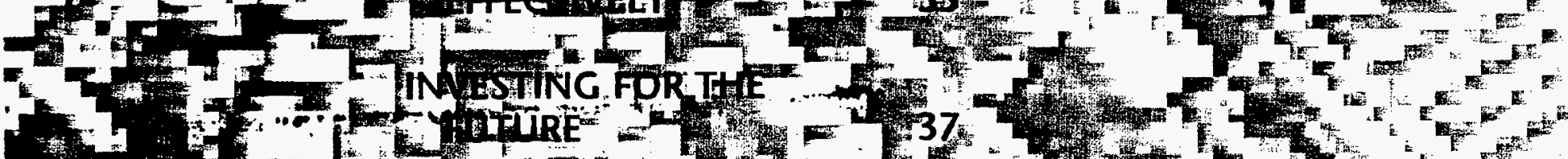
(1) 


\section{DIRECTOR'S STATEMENT}

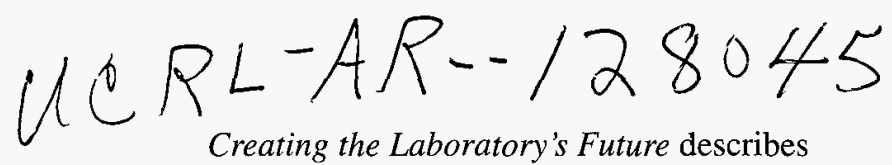

Livermore's roles and responsibilities as a Department of Energy (DOE) national laboratory and sets the foundation for decisions about the Laboratory's programs and operations. It summarizes Livermore's near-term strategy, which builds on recent Lab achievements and world events affecting our future. It also discusses our programmatic and operational emphases and highlights program areas that we believe can grow through application of Lab science and technology. Creating the Laboratory's Future reflects our very strong focus on national security, important changes in the character of our national security work, major efforts under way to overhaul our administrative and operational systems, and the continuing challenge of achieving national consensus on the role of the government in energy, environment, and the biosciences.

Since we prepared Framing the Laboratory's Future in June 1994, significant events have reaffirmed and further clarified Livermore's important national security responsibilities. Livermore is a crucial element in an integrated national program to maintain confidence in the safety and reliability of the U.S. nuclear stockpile in the absence of nuclear testing. As we move from the weapon-development paradigm of the Cold War (design, test, and build) to a weaponassurance paradigm (stockpile surveillance, assessment, and remanufacture), we must greatly increase our reliance on understanding the underlying science and technology of nuclear weapons performance. To meet Livermore's responsibilities for the nuclear weapons stockpile,

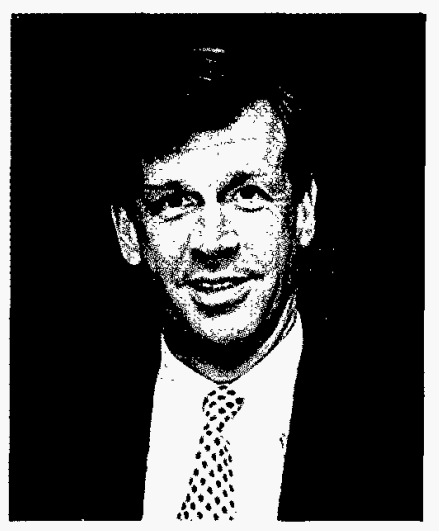

C. Bruce Tarter Director Lawrence Livermore National Laboratory

the Lab is acquiring new tools-advanced supercomputers as part of the Accelerated Strategic Computing Initiative, the National Ignition Facility for laboratory thermonuclear physics experiments, and improved diagnostic capabilities for enhanced surveillance of the stockpile.

Livermore is also supporting the DOE and other U.S. government agencies in activities to halt the spread and prevent the use of weapons of mass destruction. Science and technology are also key to these efforts; the invention and application of technology defines the limits of what is possible in terms of actions, policies, and treaties.

In Creating the Laboratory's Future, we discuss how our national security capabilities and our internal investments will provide a strong infrastructure and workforce for the Laboratory and a valuable national resource of science and technology. We are applying this resource to projects that clearly meet long-term national needs and require the approach and capabilities of a national laboratory. For example, the stewardship of nuclear materials involves nonproliferation, environmental clean-up and waste management, and civilian
The Beamlet laser (cover) is a scientific prototype for one of the 192 beamlines of the National Ignition Facility (left), a key element in the nation's program to ensure the safety and reliability of the U.S. nuclear weapons stockpile. The National Ignition Facility is being constructed at the Livermore site.

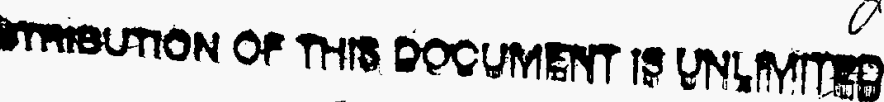

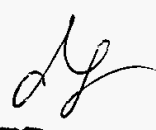

MASTER

LAWRENCE LIVERMORE NATIONAL LABORATORY 1 
nuclear power-all central to DOE's mission. Similarly, understanding the long-term impact of energy usage on the climate is a Departmental responsibility. In the biosciences, where DOE has a lead role in mapping the human genome, the nation faces comparably important challenges that require the special multidisciplinary capabilities and milestone-driven character of Livermore.

In many of these areas, we are involved in collaborations as the means to accomplish our goals, an expansion of the original E.O. Lawrence model of team science. Increasingly, our DOE programs are conducted in multilaboratory partnerships, ranging from national security to the basic sciences. Our many collaborations with academia include efforts that are leading to important discoveries in disciplines such as astrophysics and activities that will underpin scientific capabilities needed for our national security programs. We are excited about the growth of major partnerships with industry, such as interactions with computer manufacturers, commercialization of the use of lasers to enrich uranium for reactors, and the pursuit of lithography technologies needed to produce the next generation of computer chips. Over the next several years, we will gain considerable experience operating in the complex partnerships that now characterize our work with other laboratories, industry, and universities-and better understand how to design such relationships for the future.

Success in Livermore's technical programs depends on safe and environmentally sound operations, with safety continuing to be the cornerstone of our operational philosophy. In all of our operations, we are benefiting from the performance-based management approach, which is fostering a close working relationship among Livermore, the University of California, and the DOE. On the business side, we've redesigned our financial system and implemented a major costcutting initiative. The Laboratory also conducted an extensive evaluation of human resource issues, which we are using as a basis for steps designed to enhance career opportunities, ensure a better

Livermore's Programmatic Evolution

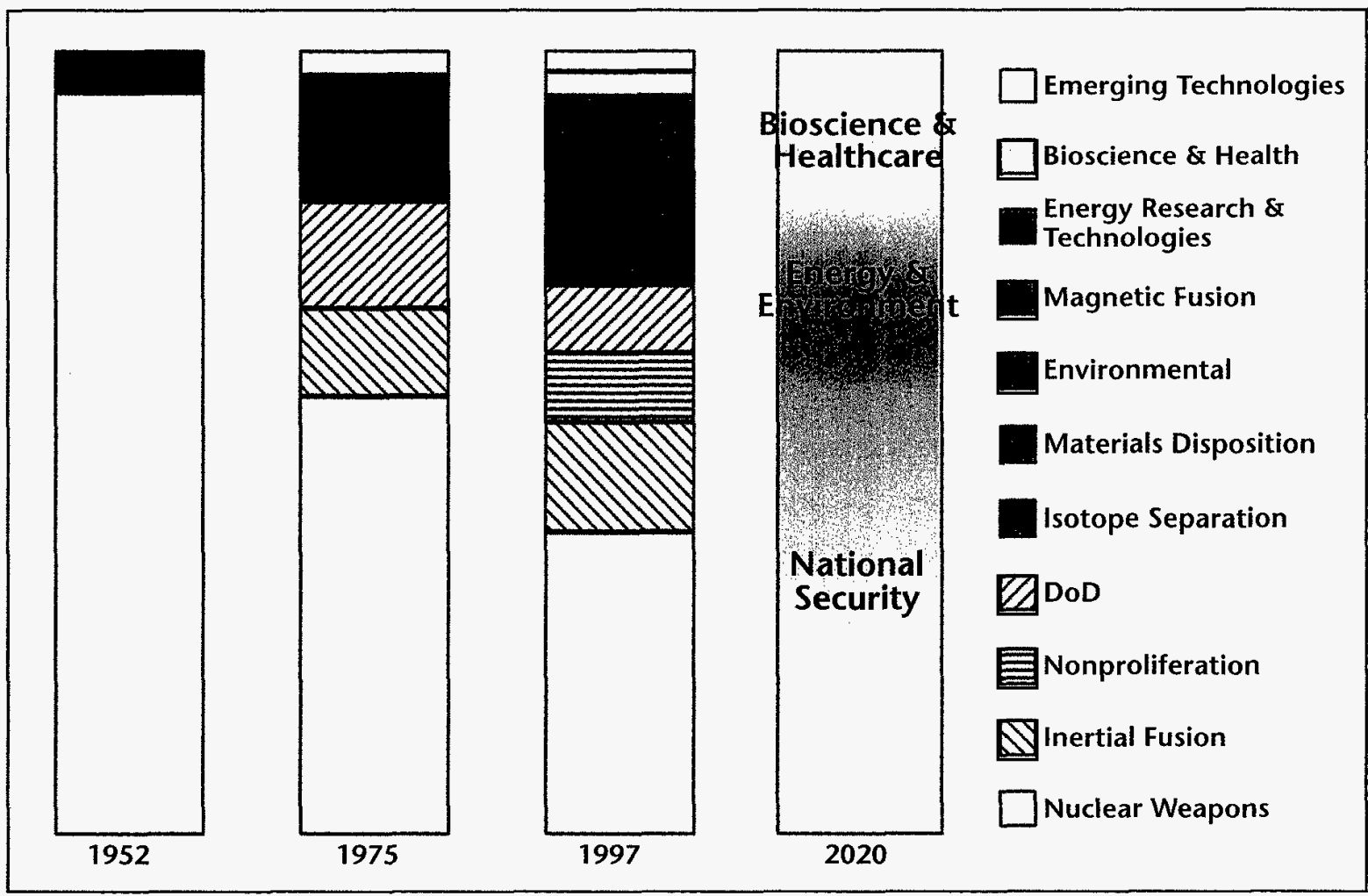


trained workforce, and create an environment in which diversity is recognized as a Laboratory strength.

Creating the Laboratory's Future describes planned activities and initiatives over the next several years. Our 10- to 25-year future is largely beyond the planning horizon of this document. In part this is because the rate of technological change is so rapid, and in part because the debate over post-Cold War research and development priorities is still very much in progress. Consequently, we indicate in the graph of the Laboratory's programmatic evolution an "emerging technologies" component of the Lab's programs in 2020. We intend to charter a long-range planning group to consider the needs and prospects for science and technology early in the next century and to assess the implications for the Lab.

The opportunity and responsibility to shape the future with science and technology continues to be the challenge that creates real excitement and a sense of purpose at our Laboratory.
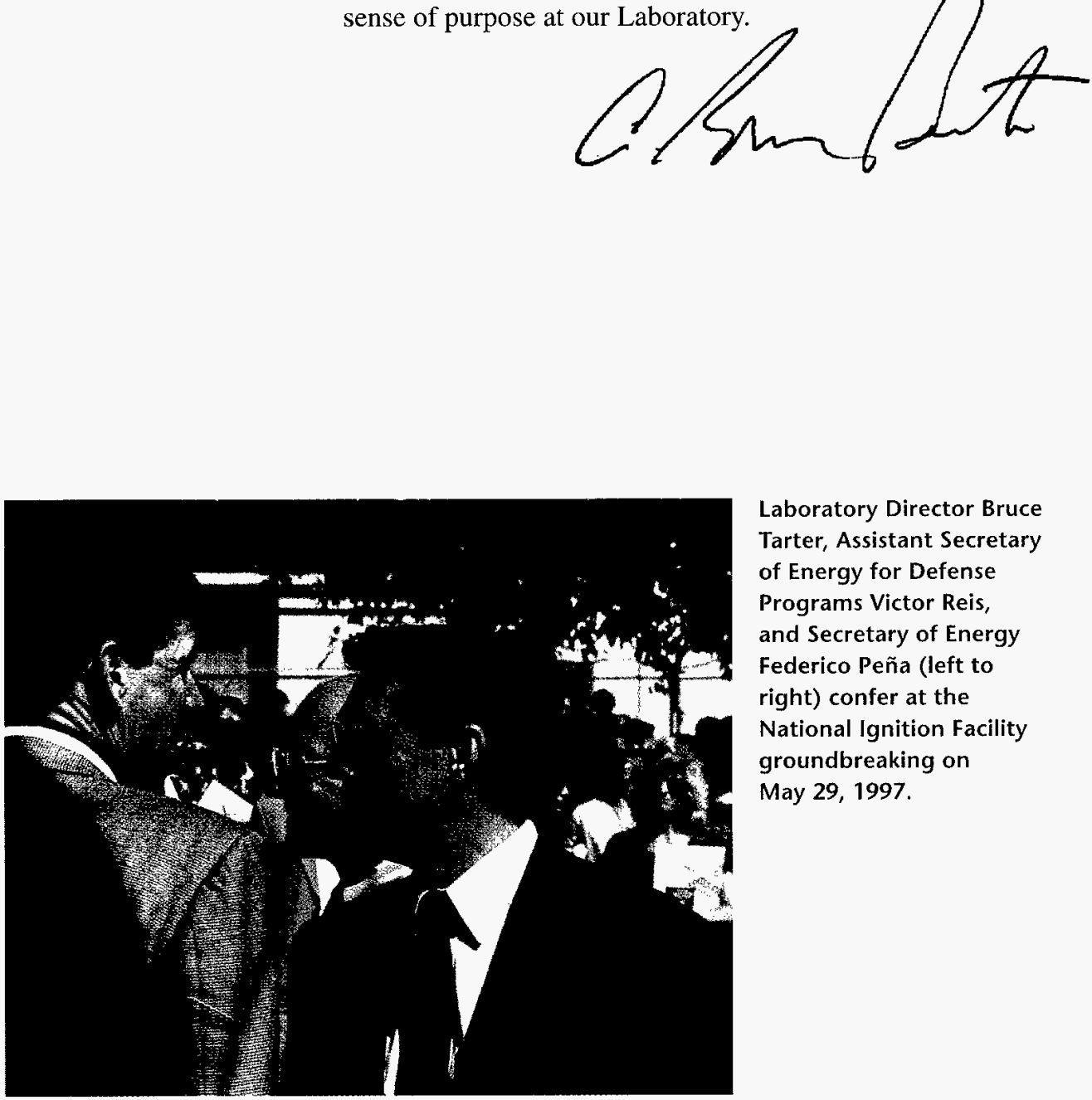

Laboratory Director Bruce Tarter, Assistant Secretary of Energy for Defense Programs Victor Reis, and Secretary of Energy Federico Peña (left to right) confer at the National Ignition Facility groundbreaking on May 29, 1997. 


\section{WHAT MAKES A NATIONAL LABORATORY}

- An essential and compelling core mission. - The national interest is at stake.

- Enduring national needs provide program continuity and enable long-term research efforts.

- The ability to solve important, difficult, realworld problems.

- Problems stretch capabilities and call for new approaches.

- Solutions have a substantial impact.

- Cutting-edge capabilities in multiple areas of science and technology.

- The research involves and integrates many disciplines.

- Multidisciplinary efforts produce a whole greater than the sum of the parts.

\section{- Science and technology that create spin-off applications.}

- Advances made for specific purposes lead to breakthrough applications in other fields.

- The spin-offs leverage the laboratory's intellectual and institutional investments.

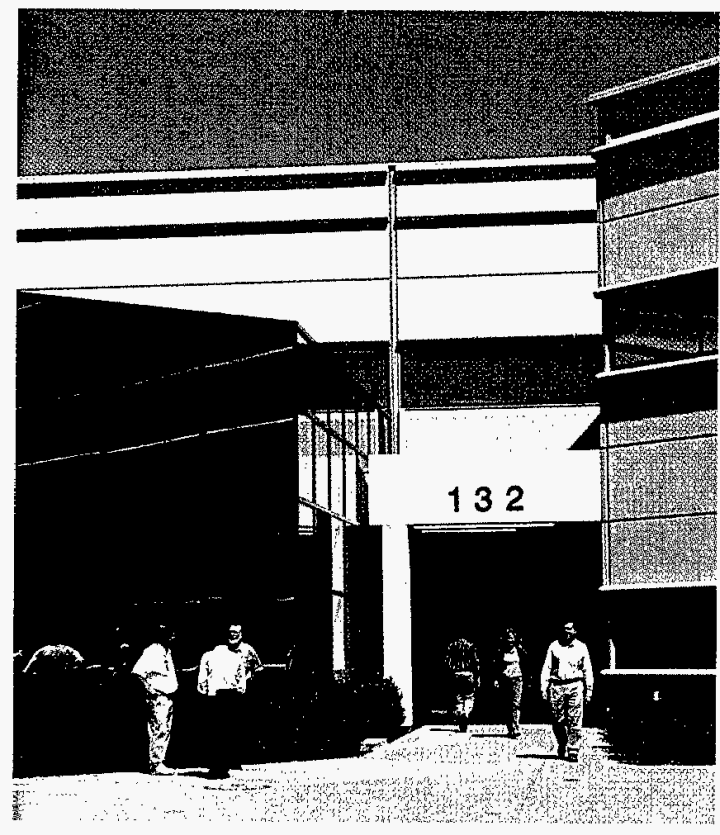

- Unique, large, and complex research facilities.

- Expanded research opportunities enable advances in science and attract diverse users.

- The capabilities foster multidisciplinary collaborations and effective partnerships.

- A committed, vital, and talented staff.

- Opportunities to do state-of-the-art work attract and sustain a talented staff.

- The culture motivates and rewards risk-taking to produce results that matter.

- Stable but evolving programs build continuity in knowledge and foster career growth.

- Partnerships that promote creativity.

- Collaborations provide broad applications for new technology.

- Training the next generation of researchers ensures future vitality and infuses new ideas.

\section{- Management, business practices, and operations that support mission goals.}

- Safe operations make progress possible in research projects with inherent technical risks.

- Managers provide visionary leadership and follow cost-effective, sound business practices.

- Prudent internal investments maintain the health of facilities and operations.
Lawrence Livermore National Laboratory is managed by the University of California for the U.S. Department of Energy. 


\section{MISSION}

Lawrence Livermore National Laboratory is a premier applied-science national security laboratory.

Our primary mission is to ensure that the nation's nuclear weapons remain safe, secure, and reliable and to prevent the spread and use of nuclear weapons worldwide.

This mission enables our programs in advanced defense technologies, energy, environment, biosciences, and basic science to apply Livermore's unique capabilities, and to enhance the competencies needed for our national security mission.

The Laboratory serves as a resource to U.S. government and a partner with industry and academia.

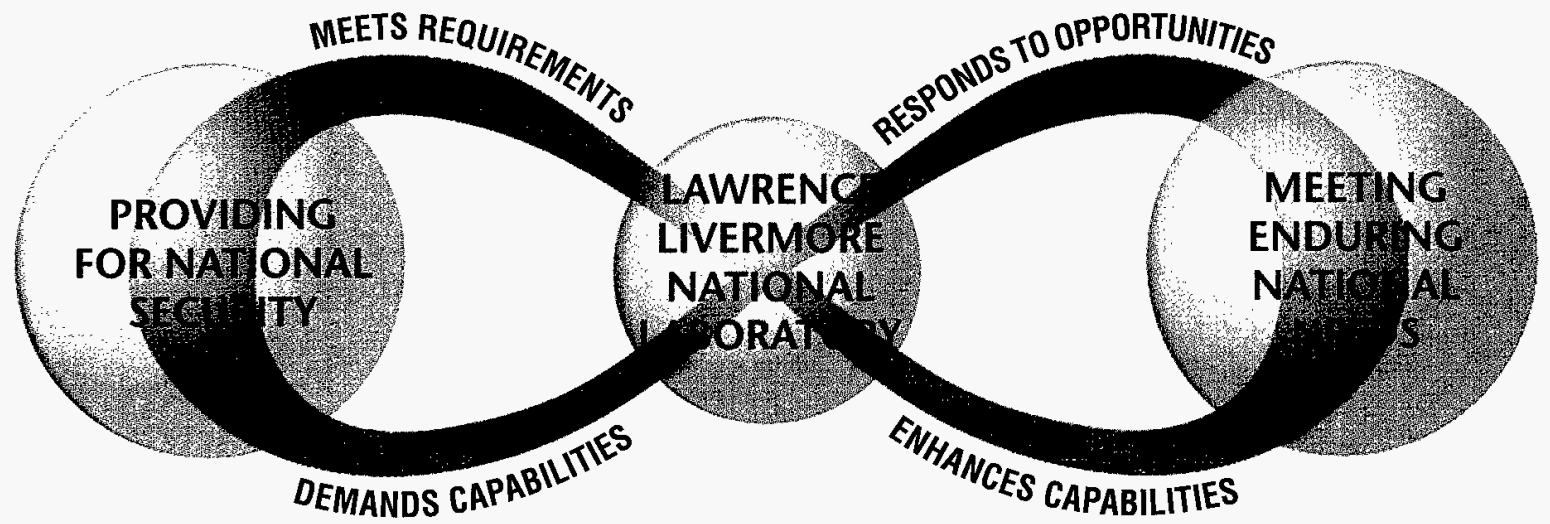




\section{VISION AND GOALS}

0

ur goal is to apply the best

science and technology to

\section{enhance the security and well-being}

\section{of the nation and}

to make the world

a safer place.

A Livermore physicist examines revalidation reports as part of formal activities to ensure continuing confidence in the safety, reliability, and performance of nuclear weapons in the stockpile.

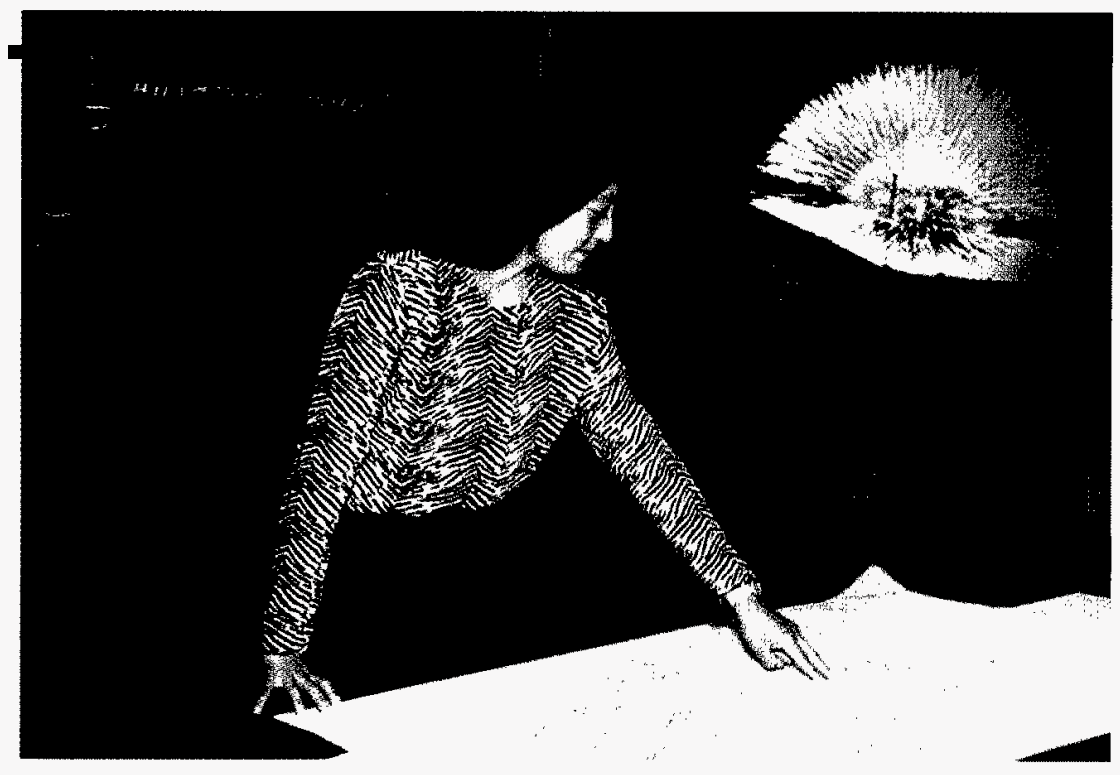

National security is the defining responsibility of Lawrence Livermore National Laboratory. We are focusing the Laboratory's efforts on two of the nation's top priorities: ensuring the safety, security, and reliability of the U.S. nuclear stockpile and preventing and countering the proliferation of weapons of mass destruction. We will provide the first-class scientific and engineering capabilities that help to make it possible for the U.S. to maintain the national deterrent while taking major steps in international nuclear arms control and arms reduction.

The realization of a world without nuclear testing - but with remaining dangers that keep nuclear deterrence and nonproliferation as central elements of U.S. security strategy - presents new challenges. As part of an integrated national effort, we must make significant advances in science and technology to maintain confidence in the U.S. nuclear stockpile under a Comprehensive Test Ban Treaty. Drawing on these advances and the special expertise of the Laboratory, we will also work with various U.S. government agencies to halt and prevent the use of nuclear, chemical, and biological weapons by developing needed technologies and analysis tools. In addition, Livermore will continue to apply its scientific and engineering capabilites to develop advanced defense technologies to increase the effectiveness of U.S. military forces.

Investments are being made at the Laboratory in computational and experimental tools that are needed to help ensure that the U.S. nuclear weapons stockpile remains safe and reliable. Livermore will have scientific computing capabilities that offer the potential for revolutionary

Microfusion targets about 3 millimeters across will be used at the National Ignition Facility to help resolve issues about the performance of nuclear weapons and to reach important goals in fusion energy research.

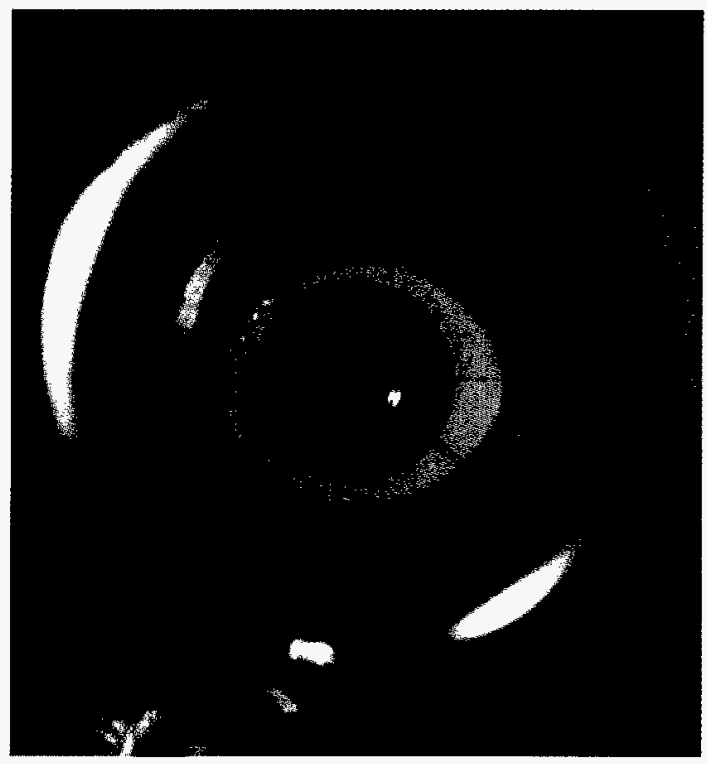


advances in many areas of science and technology as we make necessary improvements to simulation models of nuclear weapon performance. Livermore is also the site for the National Ignition Facility, which will be the world's largest laser system and will provide the means for investigating the thermonuclear physics of weapons in the absence of nuclear testing and for exploring the promise of fusion energy. These major investments shape the future of the Laboratory.

An exceptional staff with state-of-the-art research capabilities will enable the Laboratory to respond to a broad range of vital national needs. With Livermore's emphasis on high-payoff results, many projects will entail significant scientific and technical risk. We seek such challenges and will contribute where Laboratory efforts can lead to dramatic benefits for the nation.

Our special focus will remain on the critical, enduring missions of the Department of Energy and program areas that positively reinforce our national security work. Livermore will pursue

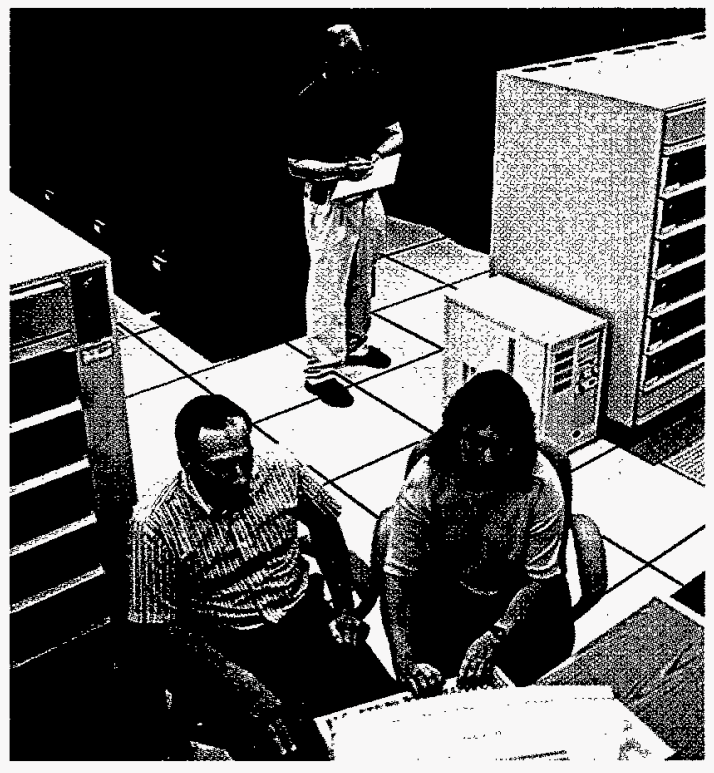

Livermore has taken delivery of the first elements of our new supercomputer for stockpile stewardship. The IBM SP also enables us to make major advances in scientific computing for other applications. projects aimed at significant, large-scale innovations in energy production to ensure abundant, clean, and affordable energy for the future.

Environmental efforts will be directed at demonstrating effective remediation technologies, advancing the science base for environmental regulation, and modeling more accurately regional weather and global climate conditions. We will also serve as an effective national technical resource in the stewardship of nuclear materials. The Laboratory's bioscience research will advance human health through efforts focused on genomics, disease susceptibility and prevention, and improved healthcare and medical biotechnology. In other fields, Livermore researchers will pursue science and technology initiatives that have the potential for major advances and that bolster the Laboratory's scientific and technological strengths.

The foundation for this diverse set of programs - now and in the future - is the Laboratory's science and technology base, which we will sustain through effectively managed internal investments. Excellence in science and technology will keep the Laboratory vibrant and healthy and able to respond to new challenges. Livermore's scientific and technological achievements will be made possible by safe and efficient operations and sound business practices. Increasingly, accomplishments will be achieved through effective partnerships with others. 


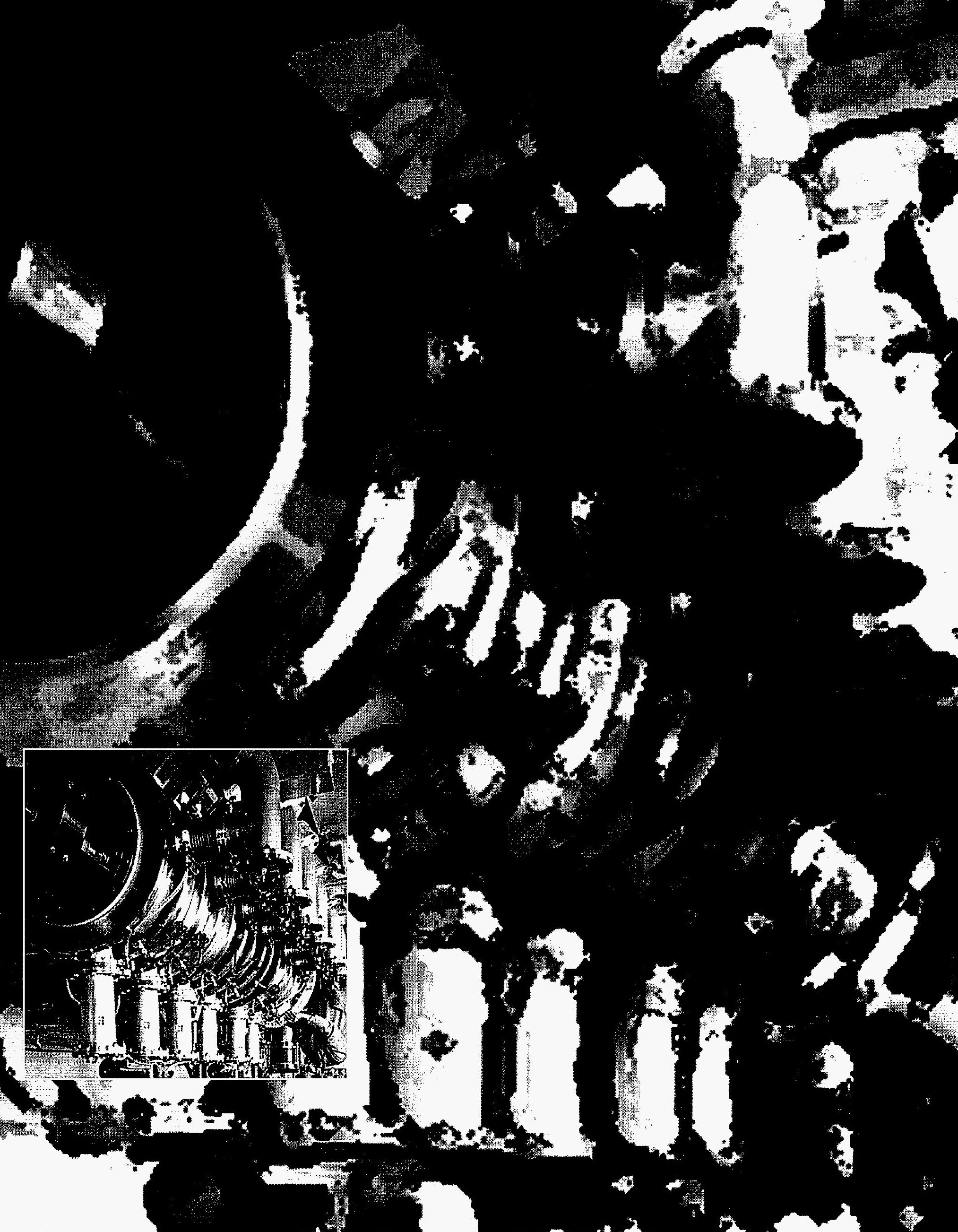

1. 


\section{$N$} the Laboratory.
The Flash X-Ray (FXR) Facility is used in hydrodynamic tests to provide detailed, ultrahigh-speed images of dense, imploding devices.
The breakup of the Soviet Union brought an end to the bilateral tensions that dominated U.S. national security policy for decades. However, the world remains a dangerous place. Economic disparities, cultural and ethnic differences, regional tensions, and uncertainties about the future can give rise to international tensions and conflict. Global interests will keep the U.S. actively engaged in world events. Thus, the nation must both prepare for anticipated security threats and expect surprises.

Threats to national security and international stability are heightened by the spread and potential use of nuclear, chemical, and biological weapons (collectively referred to as weapons of mass destruction, or WMD). At least 20 countries, some of them hostile to U.S. interests, are suspected of or known to be developing WMD. In addition, the increasing potential availability of WMD materials and technical know-how makes terrorist acquisition of such weapons a realistic possibility.

Nuclear deterrence and nonproliferation are important elements of U.S. national security policy. The U.S. is committed to halting the spread of WMD worldwide while maintaining sufficient nuclear forces to deter any adversary. As one of the Department of Energy's three national security laboratories, Livermore plays a prominent role in the Stockpile Stewardship and Management Program for maintaining the U.S. nuclear stockpile in the absence of nuclear testing. We are addressing the increasingly serious problem of WMD proliferation through a wide spectrum of analysis and technology development activities. The Laboratory provides the government with technical information and assistance to support the development of national policy on nuclear weapons, nonproliferation, and arms control matters. We also develop advanced defense technologies to increase the effectiveness of U.S. military forces.

\section{STEWARDSHIP OF THE U.S. NUCLEAR STOCKPILE}

The future course for the nation's nuclear weapons program was set in 1995, when President Clinton announced that the U.S. would pursue a comprehensive nuclear test ban. In making that decision, he reaffirmed the importance of maintaining a safe and reliable U.S. nuclear stockpile. Subsequently, the President directed necessary programmatic activities to ensure stockpile safety and reliability in the 


\section{". . I consider the} maintenance of a safe and reliable nuclear stockpile to be a supreme national interest of the United States."

President Clinton August 11, 1995 absence of nuclear testing. The Stockpile Stewardship and Management Program was developed in response to this directive, and in 1996 the President signed the Comprehensive Test Ban Treaty.

The architecture of the Stockpile Stewardship and Management Program was defined by the Record of Decision for the Programmatic Environmental Impact Statement in December 1996. The program is designed to ensure stockpile performance in an era of no new weapons development, an aging stockpile of fewer weapons and fewer types of weapons, no nuclear testing, and a production complex with reduced capacity and capability. It integrates the efforts of the three Department of Energy national security laboratories (Livermore, Los Alamos, and Sandia), the Nevada Test Site, and the four production facilities (the Kansas City Plant, Pantex, Savannah River, and Y-12 at Oak Ridge). The program is managed by the Department of Energy's Office of Defense Programs. It consists of three major elements-surveillance, assessment, and manufacturing (including the production of tritium)—which are melded together through integrated program management and formal validation processes.

\section{Integrated Program Management and Validation}

Through integrated program management, comprehensive life-extension plans for each weapon system in the enduring stockpile are being defined and will enable the laboratories and plants to anticipate most of their activities and workload. Program integration is tied to complementary formal processes for validating assessments of stockpile performance and certifying modification actions. These processes involve the Department of Energy, the national security laboratories, and the program's customer, the Department of Defense.

- Annual Certification. Annual certification responds to Presidential direction for a yearly assessment from the Secretaries of Defense and Energy on the safety and reliability of the stockpile under a Comprehensive Test Ban Treaty. Each year this certification will be based on

\section{Livermore's Contributions to the Integrated Nuclear Weapons Complex}

Independent Expertise. In an era of no nuclear testing, it is particularly important for the nation to have multiple centers of expertise about nuclear weapons. For security reasons, only a small community of people has the necessary knowledge and access to tools to deal with the details of modern nuclear weapons. Two formal shared-effort validation processes are used to assess stockpile modifications and performance: dual revalidation and annual certification. Each process relies on formal reviews and the independent expertise provided by each of the national security laboratories. There are both close cooperation and healthy competition among the laboratories in all aspects of stockpile stewardship.

Responsibility for Weapon Designs. Livermore is responsible for the W62 and W87 ICBM warheads, the B83 bomb, and the W84 cruise missile. Three of these weapons have all modern safety features.

Special Facilities at Livermore. Each of the national security laboratories operates unique experimental facilities used by all of them to obtain data for resolving stockpile issues. For example, Livermore's High Explosives Applications Facility is the most modern facility for high-explosives research in the world. The Nova Laser Facility is a unique facility for weapon physics experiments; its capabilities will be greatly surpassed by its successor, the National Ignition Facility. 
Annual certification, which includes rigor-

ous internal and

external review

processes, will provide

an important focus for

stockpile stewardship

and life extension

activities at Livermore.

A stainless-steel containment vessel is used for high-explosives experiments at HEAF,

Livermore's High-

Explosives Application

Facility.

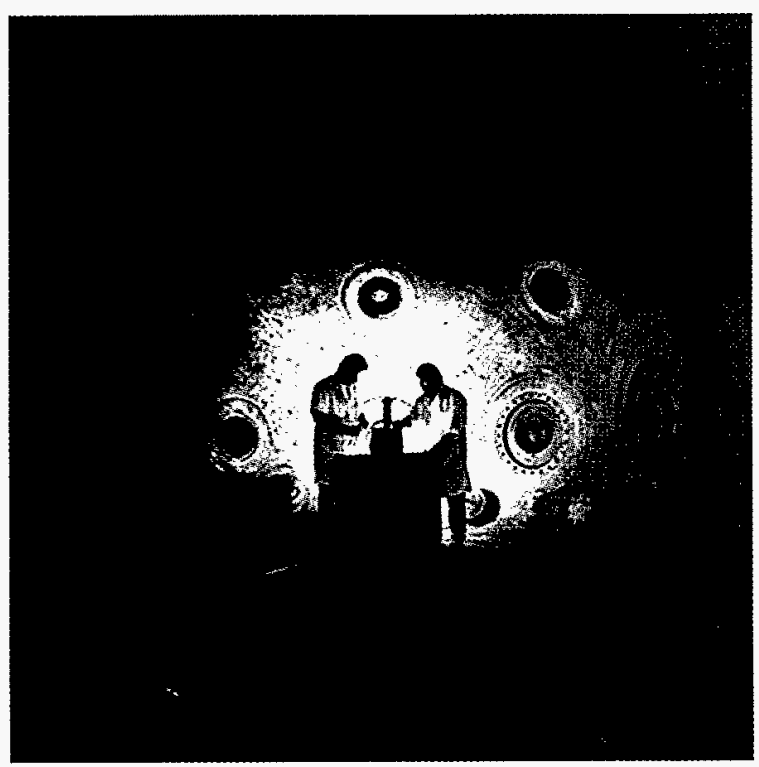

over time as they cycle through temperature changes and are exposed to radiation and gases released from other materials in the weapon. Surveillance with predictive capabilities will permit a systematic program of refurbishment and preventative maintenance. With planned production capacity and capabilities, we must be able to predict weapon performance 10 to 15 years in the future. Such predictive capabilities require an in-depth understanding of how aging alters the physical characteristics and properties of weapon materials.

- Subcritical Experiments. We must acquire a fundamental understanding of plutonium in general and of aging plutonium in particular. Plutonium has properties that are critical to the performance and safety of nuclear weapons, but it is one of the most complex and least understood of all metals. Livermore and Los Alamos will conduct subcritical (no-nuclear-yield) experiments at the Nevada Test Site to gather information about plutonium at conditions similar to those that occur during nuclear weapon operation.

We have created state-of-the-art underground laboratories at the Nevada Test Site to study highly shocked plutonium. Streak cameras and holographic techniques are used to record data in these subcritical experiments.
We are augmenting our ability to predict and detect aging-related changes that could degrade weapon safety or reliability and jeopardize stockpile performance. Weapons in the U.S. nuclear stockpile are now older on average than ever before. Materials inside a weapon degrade 
- Nondestructive Surveillance Techniques. Livermore, Los Alamos, and Sandia will develop new sensors and techniques for use in stockpile surveillance that are more sensitive to physical changes in the weapon and do not affect weapon components when used in inspections. For example, we are testing a new technique that is extremely efficient and nonintrusive for sampling evolved gases within stockpile weapons.

\section{Assessment}

We will evaluate the significance of issues that arise in surveillance and assess their effect on weapon safety and performance. When modifications are deemed necessary, viable options for refurbishing or replacing specific warhead components must be determined and evaluated. Assessments will be based on demonstration, using archival data together with non-nuclear experiments and experimentally validated computational models. We will bring into operation new scientific capabilities that are needed to make these assessments. These tools will also enable experienced weapons scientists and engineers to train the next generation of stockpile stewards.
- Higher-Resolution Computational Models. High-resolution, three-dimensional weapon physics and engineering models are needed to assess the performance of nuclear weapons and the conditions affecting weapon safety. Through the Accelerated Strategic Computing Initiative, the national security laboratories are working with U.S. industry to develop successively more powerful supercomputers, leading to a 100,000 fold increase in computational speed and data capacity. Each advance will represent the world's largest, fastest computer. Computer scientists will be challenged to develop algorithms and simulation codes that take full advantage of the parallel architecture of the new machines. Using the first elements of the Laboratory's next-generation supercomputer (the IBM SP, delivered in September 1996), weapons experts are already benefiting from unprecedented new capabilities.

- Improved Physics in Computational Models. To make full use of increases in the resolution of weapon physics and engineering simulation codes, we must also improve the science in the codes. We will combine theoretical work with a variety of laboratory experiments to develop improved, validated physical databases and physical models for simulation codes. We must understand in detail the interaction of matter
The Accelerated Strategic Computing Initiative (ASCI) will provide a rapid expansion of Livermore's computing capabilities, here measured in computer speed (millions of operations per second).

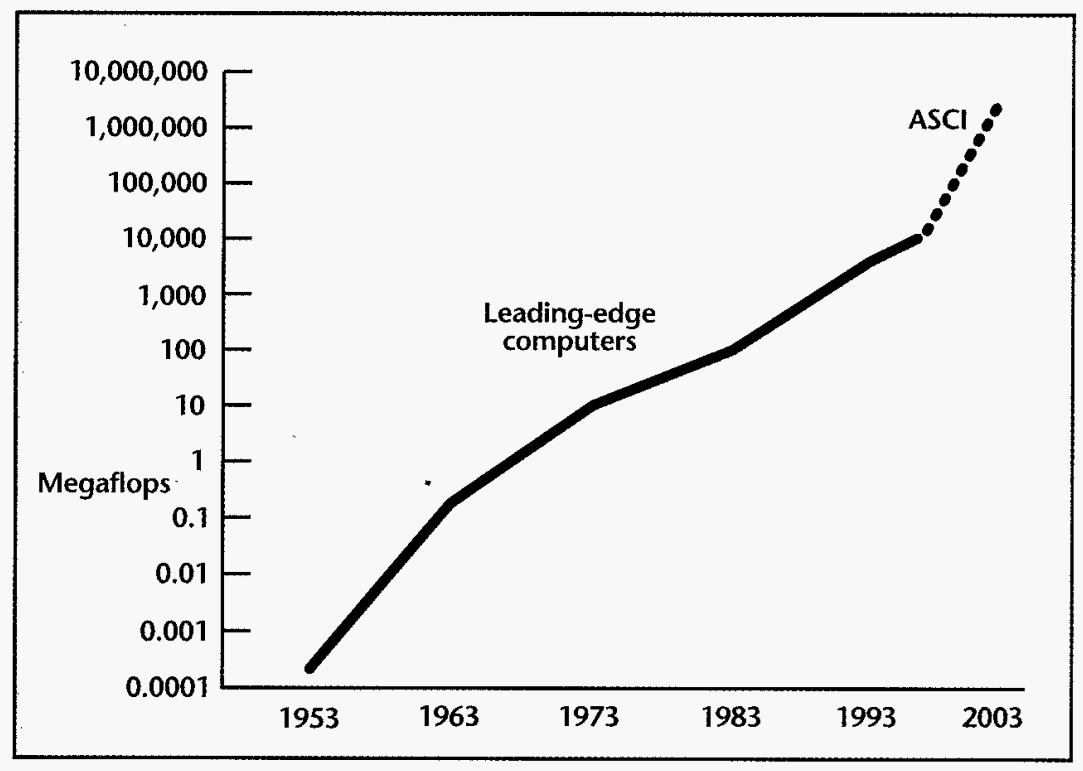


"The National Ignition

Facility will unleash

discoveries that we

can only now dream

of .... The NIF will

help us unleash the

power of the heavens

to make the earth a

safer place."

Federico Peña

Secretary of Energy

May 29, 1997 with radiation and the properties of materials at extreme conditions of temperature and pressure. We will combine multiscale modeling with experiments to explore material properties from the quantum level to the atomic level to much larger scales.

- Thermonuclear Physics Experiments. Laboratory experiments of weapons physics, including fusion burn, at relevant conditions of temperature and pressure are needed to resolve important stockpile issues and validate computational models. The National Ignition Facility (NIF), which will contain the world's largest laser, is being constructed at Livermore and will provide the only experimental means of studying fusion burn. In addition, the NIF will be a critical next step in the development of inertial confinement fusion as an environmentally attractive energy source and will serve as a user facility for a wide range of fundamental research. The NIF will be invaluable in attracting and training the next generation of stockpile stewards.

- Improved Hydrodynamic Experiments. Hydrodynamic experiments provide crucial data on a nuclear weapon's high-explosive detonation and implosion phases. By upgrading the Flash $X$-Ray Facility to provide full containment of debris from hydrodynamic experiments, we will greatly facilitate the environmental management of these essential experiments. Livermore and Los Alamos will also pursue technology development for a next-generation facility, the Advanced Hydrotest Facility, to obtain multiple views at multiple times during an experiment, a vast improvement over current capabilities.

\section{Manufacturing}

Stockpile nuclear weapons must be refurbished periodically, and the replacement parts, materials, and processes must be certified. The development of replacement parts will be integrated with the development of new materials and manufacturing processes. This concurrent engineering approach, with its close collaboration among the laboratories and the nuclear weapons production plants, will reduce costs and increase the efficiency of the production complex. To meet the anticipated refurbishment workload, production facilitiesincluding those for tritium-must be flexible, reliable, highly capable, yet affordable.

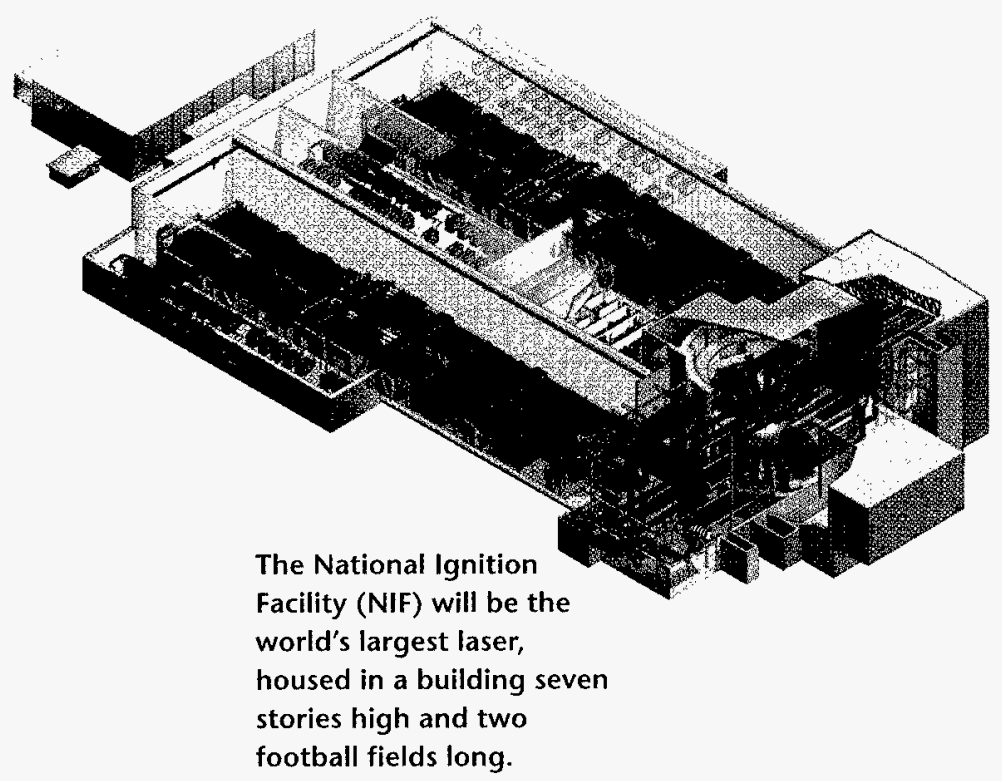


- Advanced Manufacturing Technologies. We will team with the production plants to develop advanced manufacturing technologies that will reduce defects, improve production yields, and lower costs. We will draw on Livermore's extensive chemistry, materials science, and engineering expertise to develop improved materials and manufacturing technologies for replacement weapons parts. For example, Livermore's ultrashort-pulse laser technology will be incorporated into an extremely precise laser-cutting system that will reduce costs and wasted materials in weapon refurbishment activities.

\section{STEMMING PROLIFERATION OF WEAPONS OF MASS DESTRUCTION}

Dealing with the complex and serious threat of weapons proliferation is a critical national priority. Halting the spread and preventing the use of weapons of mass destruction (WMD) require the integration of technology and policy. The national laboratories are working with the various U.S. government agencies that have responsibilities in this area.
At Livermore, we are applying nuclear expertise and other capabilities to the challenge of nuclear nonproliferation. In response to recent legislation calling for enhanced U.S. capabilities against proliferation of all types of WMD, we are also developing the technologies, analysis tools, and expertise needed to help stem the proliferation of chemical and biological weapons. Livermore's program in nonproliferation, arms control, and international security is tackling WMD proliferation across the entire spectrum of the threat-prevention, reversal, response, and avoiding surprise.

\section{Proliferation Prevention and Arms Control}

Prevention is the first level of defense against WMD proliferation. Livermore has a long history of policy analysis and support for U.S. arms control activities, dating back to the atmospheric test ban negotiations and the Strategic Arms Limitation Treaty talks of the 1960s. Currently, we are conducting research and development on technologies for monitoring the Comprehensive Test Ban Treaty and the Chemical Weapons Convention. We will provide technical and analytical support to U.S. negotiators for the START III talks, which are aimed at further reducing U.S. and Russian nuclear arsenals. We will also continue to be extensively involved in activities to safeguard nuclear materials worldwide.
We developed a waste-free means of cutting open weapon pits (left) that are excess to national security needs. As the next step leading to permanent disposal, the plutonium is then extracted and converted to an oxide using the Livermore-developed hydride/oxidation (HYDOX) process (right).

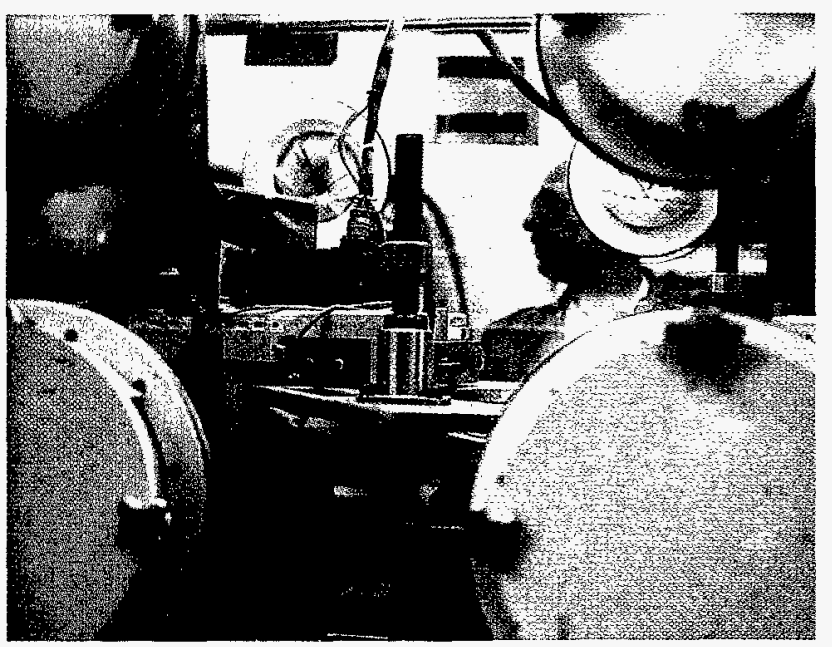


We will provide U.S.

decision makers with

capabilities for analyz-

ing proliferation

activities and evaluat-

ing the consequences

of possible interdic-

tion options.
- Support for the Comprehensive Test Ban Treaty. We will continue to assist the U.S. effort to implement the Comprehensive Test Ban Treaty by providing personnel to support the negotiations preparing for entry into force of the treaty and by pursuing research to improve treaty compliance monitoring. We will develop the data and databases needed to compute regional seismological corrections and monitor with high confidence specific regions of interest for lowyield nuclear tests. We will also investigate the use of alternatives to seismic signatures to detect evasively conducted nuclear tests.

- Nuclear Material Protection and Control. We will expand Livermore's collaborations with facilities in Russia and the other Newly Independent States to improve the protection, control, and accounting of nuclear materials. Researchers will also work with Russian counterparts to reduce the inventories of nuclear weapons materials of both countries, including the development and validation of methods to confirm that inspected fissile material originated from the dismantled nuclear weapons.

- Fissile Material Disposition. The dismantlement of thousands of nuclear weapons by both the U.S. and Russia will require the disposition of large quantities of weapons materials. Technical options for the permanent disposition of plutonium are being investigated at Livermore, the other national laboratories, and counterpart institutions in Russia. Livermore will focus on developing technologies to embed plutonium in glass or ceramic materials.

- Integration of Policy and Technology for Global Security. We recently formed the Center for Global Security Research to bring together scientists, technologists, and the policy community to examine the ways in which technology can enhance international security. Through collaborative projects, the Center will study such topics as the security implications of emerging technologies, technical options for bolstering security, implications of a START III agreement, and the future role of military forces.

\section{Proliferation Detection and Defense Systems}

The nation must be able to detect weaponsrelated activities and evaluate options for stopping potential proliferants from successfully acquiring WMD. We will build on the Laboratory's broad base of relevant expertiseincluding genomics, microfabrication, sensors and remote monitoring, lasers, atmospheric science, computational modeling, intelligence analysis, and emergency response-to develop needed capabilities and technologies.
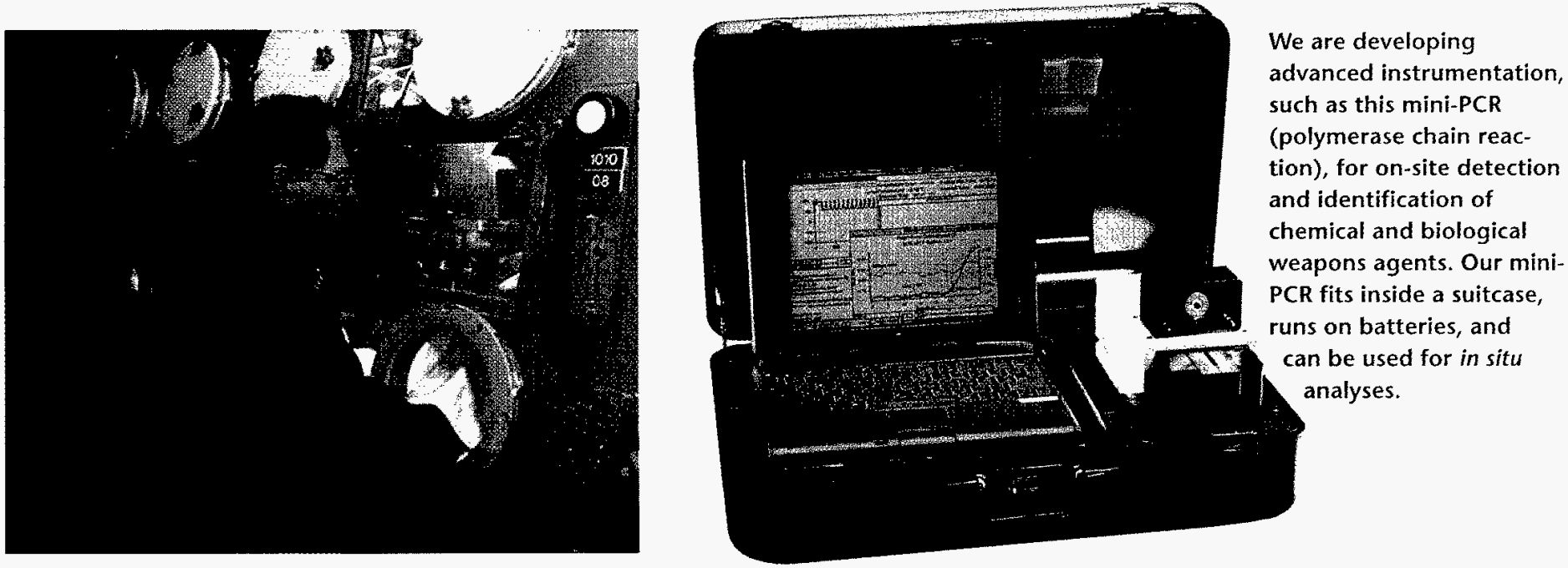
- Proliferation Detection Technologies. We will develop sensitive, long-range standoff sensors for measuring trace amounts of airborne effluents that are indicative of specific processes occurring within suspect weapons production facilities. We will also develop local sensors for long-term continuous monitoring of inherently short-range signatures (e.g., radiation). In addition, we will develop networks of sensors to protect critical areas, such as military bases, from ground-delivered nuclear devices and biological weapons.

- Counterproliferation Analysis and Planning. We will apply our expertise in countryspecific analysis of proliferation activities, weapons development, and computational modeling to provide U.S. decision makers with enhanced capabilities for analyzing weapons proliferation activities and the consequences of possible interdiction options. We will develop versatile and powerful tools for assessing the proliferation activities of foreign countries, ascertaining the specific function and location of major production sites, and identifying critical production activities that, if interdicted, would halt the proliferation effort.

\section{Counterterrorism and Incident Response}

We are augmenting Livermore's long-standing capabilities in nuclear emergency response with similar capabilities for chemical and biological weapon emergencies. The Laboratory's efforts are integrated with those of the other laboratories and government agencies that would respond to a WMD incident. We will continue to devise strategies for dealing with the threat of WMD terrorism and develop improved techniques for detecting and disabling WMD devices. We will also pursue an initiative to counter nuclear smuggling to prevent nuclear weapons and nuclear materials from falling into the wrong hands.

- Responding to the Proliferation of Chemical and Biological Weapons. We will develop detectors and sensor systems for remote monitoring and characterization of chemical and biological proliferation activities as well as field-portable instrumentation for on-site analysis in the event of a chemical or biological weapon attack.

- Counter-Nuclear-Smuggling. Livermore has unique resources for dealing with actual or alleged cases of nuclear smuggling. For example, we have available the instrumentation and expertise for characterizing virtually any compound and identifying nuclear, chemical, or biological signatures of WMD activity. In addition, we developed and now staff the Department of Energy's Threat Credibility Assessment Center, located at Livermore. The Laboratory's strengths in sensor systems, remote monitoring, and information analysis will be used as part of a collaborative national initiative to identify and interdict nuclear smuggling.
Highly interactive simulation models are used for military training and security analysis at Livermore's Conflict Simulation Laboratory.
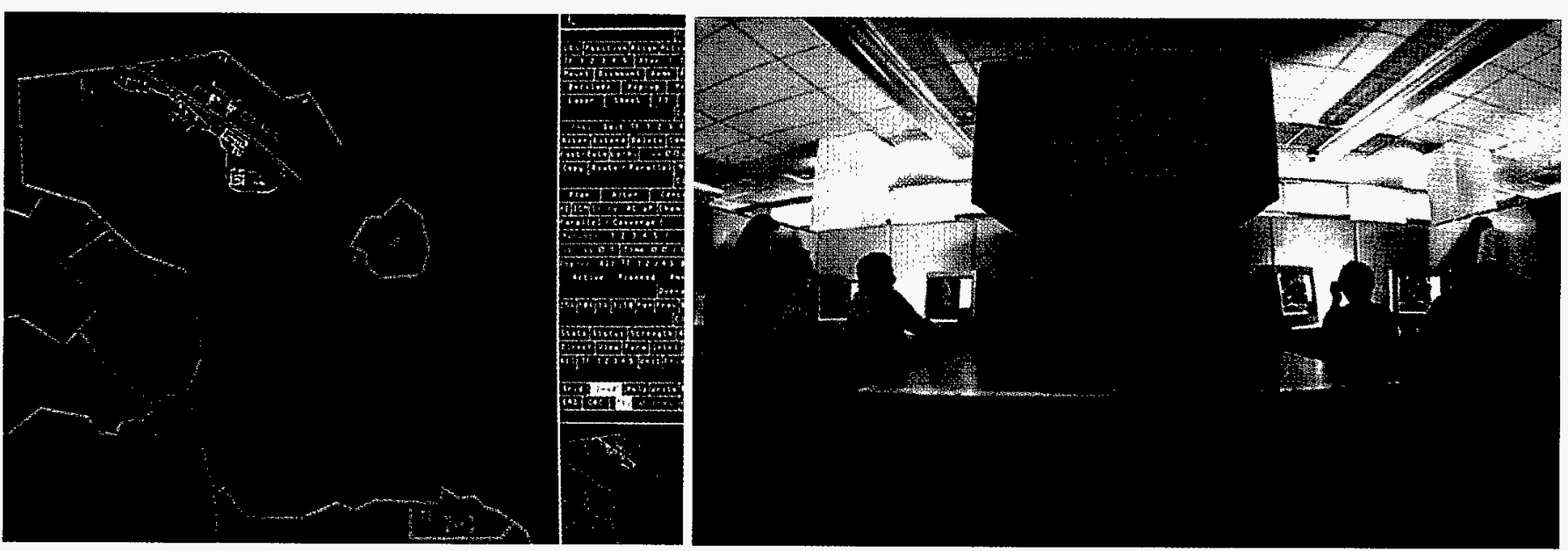


\section{We will build on the scientific and technical capabilities developed for the Laboratory's stockpile stewardship and nonproliferation missions to pursue advanced technologies for the Department of Defense.}

\section{Avoiding Surprise}

The nation must avoid being surprised by foreign WMD activities. For decades, Livermore has used its technical knowledge about the design and testing of nuclear explosive devices to assess foreign nuclear weapons programs and nuclear proliferation risks. We will continue to integrate this knowledge with specifics about each country's nuclear capabilities and with our understanding of the nontechnical issues that motivate nuclear programs. Livermore's analyses will support the U.S. intelligence and policy communities, providing valuable technical assistance to policy makers and diplomats as they develop strategies for the U.S. response to international activities.

\section{MEETING NEW MILITARY REQUIREMENTS}

The Department of Defense must define and implement the military strategy, force structure, modernization programs, and defense infrastructure to meet ever-shifting future threats to U.S. national security. Recent studies have defined a U.S. "military of the future" that is technologically superior and dominant enough to win quickly, decisively, and with minimum casualties. Consistent with national budget constraints, the technologies that provide this dominance must be cost effective and available in a timely manner.
We will build on the scientific and technical capabilities developed for the Laboratory's stockpile stewardship and nonproliferation missions to pursue advanced technologies for the Department of Defense. We will focus on areas where Livermore's special skills match identified needs.

- Quick and Decisive Military Operations. The U.S. military's ability to conduct operations quickly and decisively will depend heavily on advanced sensors, information technologies, and predictive meteorology capabilities. Livermore will use its demonstrated strengths and capabilities to pursue innovations in each of these areas.

- Precision Weapons Systems. Livermore will contribute its expertise in energetic materials, advanced conventional munitions, laser and electro-optics systems, conflict simulation models, and consequence analyses to the development of precision weapons systems that will allow the U.S. military to destroy adversary targets while minimizing collateral casualties.

- Effective Protection of U.S. Forces. The Laboratory will pursue technologies pertinent to theater ballistic missile defense and the detection of chemical and biological agents in order to protect U.S. forces against chemical and biological weapons.

- Efficient Operations. Livermore's conflict simulation capabilities will be applied to logistics issues to investigate means for efficient supply of equipment to U.S. forces, which can make a decisive difference early in a military operation and dramatically reduce overall costs.

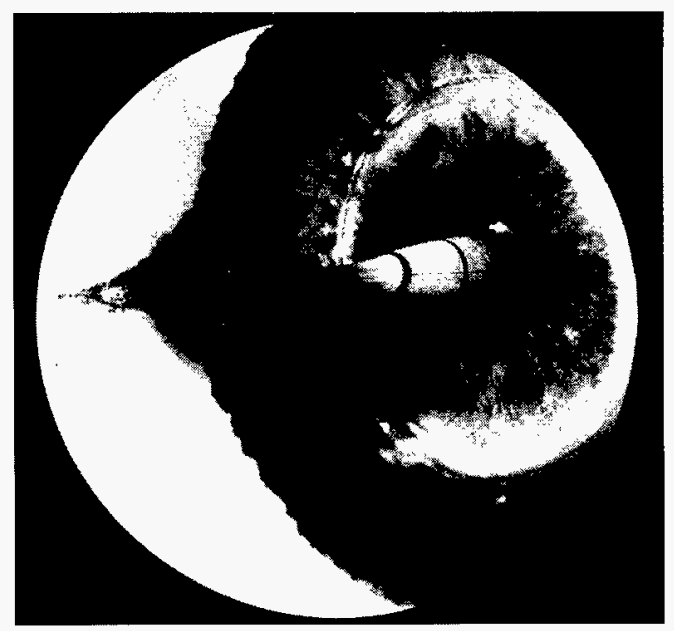

An explosively formed jet of metal ( 10 centimeters long) speeds to the left at 8 kilometers per second as it is recorded by a streak camera. At Site 300, we are demonstrating shapedcharge technology for use against very hard targets. 


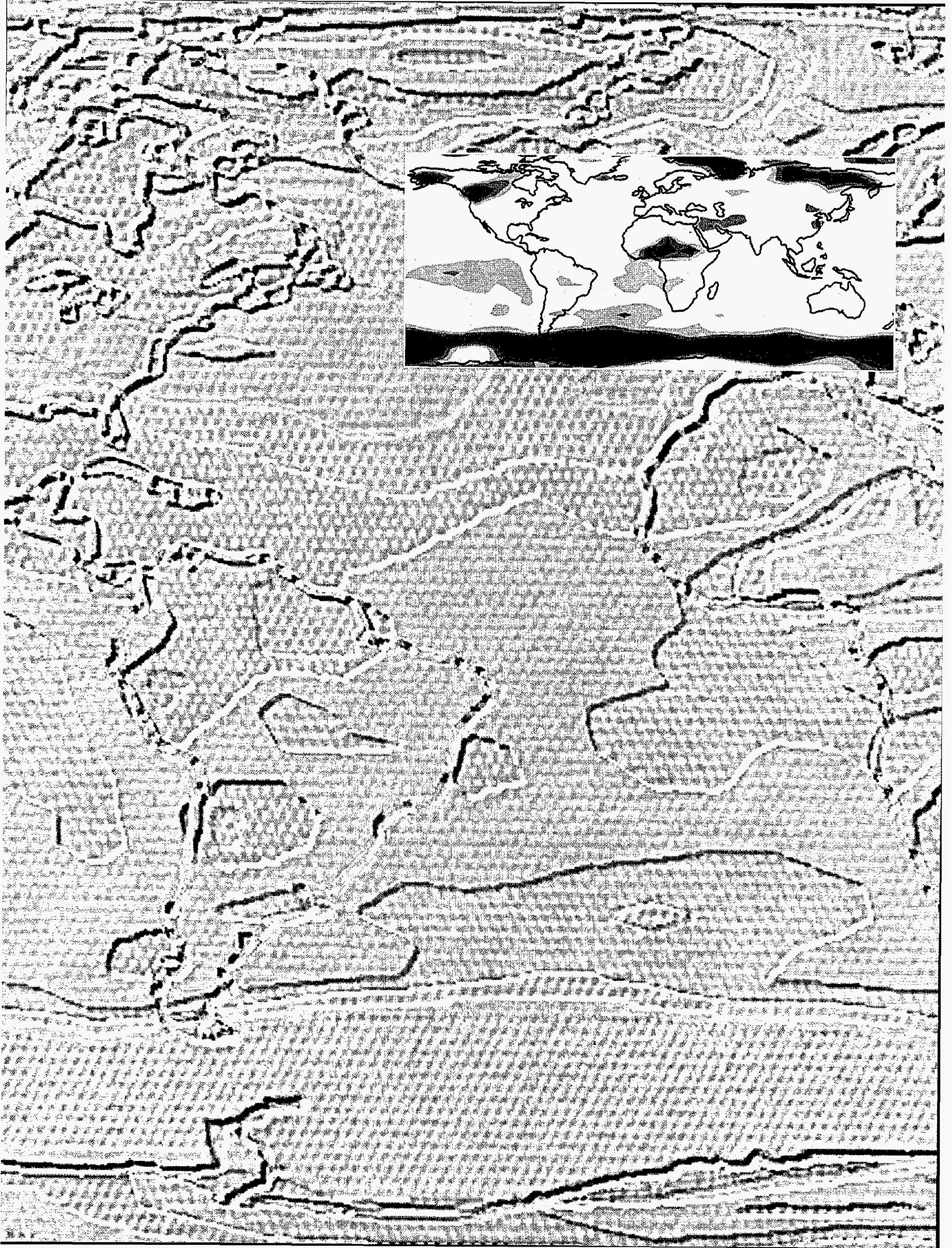




\section{MEETING ENDURING NATIONAL NEEDS}

$W$

e seek challenges where

taking technical risks

can lead to high payoffs and

make important

\section{contributions to}

national well-being.
The Department of Energy has enduring missions that are vital to the national interest. In addition to its national security mission, the Department's priorities include enhancing the nation's energy security and developing and making available clean energy, cleaning up former nuclear weapons sites and finding a more effective and timely approach to nuclear-waste disposal, and leveraging science and technology to advance fundamental knowledge and economic competitiveness.

Livermore's strengths are well matched to the Department's needs, particularly in areas with high payoffs that entail significant scientific and technical risk. We pursue major projects where we can make unique and valuable contributions. These activities build on and reinforce the Laboratory's key strengths. The nation benefits from the application of Livermore's special skills to a wide range of national problems and from the cross-fertilization of ideas that occurs. In turn, program diversity keeps the Laboratory vital and helps to sustain the multidisciplinary base needed for national security work.

\section{ENERGY SECURITY AND LONG-TERM ENERGY NEEDS}

The Laboratory's research focus will be on significant innovations in energy production and usage. The availability of affordable energy has been the foundation of U.S. prosperity and economic growth. At present, energy is relatively cheap and abundant and is of little concern to most Americans. However, the U.S. imports about $50 \%$ of the oil it consumes, and much of the world's supply comes from a politically volatile Middle East. With total world energy consumption growing at nearly $20 \%$ per decade, competition for energy in the international marketplace will increase dramatically.

The future security of our nation will depend on access to abundant energy sufficiently clean to preserve the environment. We will work with the Department of Energy to design an energy research and development portfolio that meets the needs of the 21 st century. Livermore will pursue programs in fusion energy, nuclear fuel cycle improvements, nuclear systems safety, and hydrogen fuel.

\section{Fusion Energy}

Energy production from nuclear fusion is a long-standing goal at Livermore. Research efforts build on and reinforce our national security activities, which provide Livermore the advantage of combined strengths in nuclear science, scientific computing, laser technologies, and engineering. These capabilities will focus on identifying and pursuing the most promising path to full-scale deployment of fusion power. We will conduct inertial fusion experiments with the National Ignition Facility and pursue advanced magnetic confinement fusion schemes. We also seek to maintain the Laboratory's major role in the U.S. program on the International Thermonuclear Experimental Reactor.
In global climate research, Livermore applies advanced computing techniques to assess the effects of carbon dioxide and sulfate aerosols. 
In the National Ignition

Facility, we expect to

create-for the first

time ever in a labora-

tory setting-bursts of

self-sustaining fusion

reactions.
- Demonstration of Inertial Fusion Ignition and Burn. In the National Ignition Facility, we expect to create - for the first time ever in a laboratory setting - bursts of self-sustaining fusion reactions. This physics demonstration will be conducted in parallel with a research program on fusion driver concepts (ion-beam accelerators and lasers) to meet the efficiency and repetitionrate requirements of inertial fusion power plants.

- Magnetic Spheromak Experiments. The spheromak is an alternative to the tokamak that might lead to smaller, less-expensive fusion reactors. We will pursue experiments to achieve sustained spheromak operation and will resolve key scientific issues to advance the design of magnetic fusion systems.

- Integrated Fusion Modeling. We will use the unprecedented computing capability that we are acquiring to enhance inertial fusion simulations and large-scale integrated modeling of magnetic fusion experiments. The latter goal, probably a decade away, will include coupling individual magnetic fusion physics codes using the parallel architecture of the new supercomputers used for stockpile stewardship.

\section{Atomic Vapor Laser Isotope Separation}

In a 20 -year-long effort, Livermore has been developing the atomic vapor laser isotope separation (AVLIS) process for enriching uranium for reactor fuel at reduced cost and environmental impact. The goal culminates with the largest technology transfer in government history-the successful commercialization of AVLIS by the U.S. Enrichment Corporation (USEC).

- Production-Plant-Scale AVLIS. USEC is taking preliminary steps to construct a production AVLIS facility, and Livermore has the lead role for design and deployment of the special process equipment. Working for the USEC, we will demonstrate uranium-AVLIS at production-plant scale and assist in plant design and deployment.

\section{Advanced Energy Technologies}

We will partner with U.S. industry to develop hydrogen fuel technologies, advanced fuel cells and flywheels for energy generation and storage, and high-precision manufacturing technologies that reduce waste and consume less energy.

- Hydrogen Fuel. In a collaborative effort of national laboratories and U.S. industry, we will develop technologies to use hydrogen fuel as a clean, accessible alternative to petroleum products for use in transportation systems. We will evaluate systems issues and tradeoffs, establish partnerships for advanced demonstration programs, and develop technologies for efficient hydrogen production, storage, and use. The overall program goal is to introduce into the marketplace environmentally benign automobiles that are performance competitive with gasolinepowered vehicles.

The Accelerated Strategic Computing Initiative (ASCI), required for stockpile stewardship, enables the Laboratory to respond to other program opportunities.

\section{Opportunities Created by Advanced Computing}




\section{We are at the thresh- \\ old of a new era in \\ environmental simula- \\ ENVIRONMENTAL ASSESSMENT AND MANAGEMENT}

tions, with the poten-

tial to assess and

predict environmental

phenomena with

unprecedented speed

and accuracy.
The Department of Energy has major environmental responsibilities. Dealing with the legacy of Cold War nuclear weapons production is a monumental task, estimated to cost $\$ 200$ billion to $\$ 350$ billion. In addition, the Department shoulders the broad responsibility of understanding - and anticipating - the local, regional, and global impacts of energy use and other human activities on the biosphere.

Livermore will assist the Department and the nation in two significant ways. First, at the Livermore site we have developed and field tested broadly applicable technologies for environmental remediation. Second, the Laboratory will greatly enhance the nation's ability to predict and respond to manmade environmental hazards and natural changes that affect weather or climate.

\section{Environmental Remediation and Regulation}

The Laboratory has well-demonstrated capabilities for measurement of organic and radioactive contaminants, science-based risk assessment, and environmental remediation. Livermore completed the first cleanup of a major underground fuel contamination at a national laboratory. We also have developed unique tools for predicting the transport, deposition, and human impact of radioactive and toxic materials in the ecosystem. In addition to their contribution to environmental management of the Livermore site, these capabilities are applied to national security work at the Laboratory (e.g., technologies to monitor proliferation activities) and projects concerning important environmental issues.

As an example, we recently used these tools to examine underground fuel tank contamination in California; the study's findings may save over $\$ 1.5$ billion in cleanup costs. Livermore is able to assist regulatory agencies in placing cleanup standards on a science-based footing.

- Accelerated Site Cleanup. We will propose to the Department of Energy an Accelerated Cleanup Initiative to demonstrate at Livermore novel, cost-efficient technologies for soil and groundwater cleanup. Livermore's cleanup requirements are similar to those for many Department of Defense sites, which must undergo remediation before release for public use. We will also offer to collaborate with the Department of Defense in cleanup technology demonstrations that will include corporate partners. These activities will validate the performance and the economics of the new technologies.

- Improved Environmental Toxicology. We will form an academic-industrial consortium to develop a realistic, scientific risk basis for environmental regulation of toxic chemicals. Livermore's Center for Accelerator Mass Spectrometry offers an extremely sensitive measurement capability for determining the mutagenic and carcinogenic potency of common chemical pollutants. We will include the regulatory agencies in this activity to ensure their confidence in and use of the results.

\section{Assessment and Prediction of Atmospheric Processes}

With the advent of terascale supercomputing at the Laboratory, we are at the threshold of a new era in environmental simulations, with the potential to assess and predict environmental phenomena with unprecedented speed and accuracy. Livermore is advancing global climate 
We are developing regional predictive capabilities for precipitation and runoff that are operationally useful for weather emergencies and resource management. simulation by improving the models of dynamical and chemical processes in the atmosphere, coupling models of atmospheric and oceanic circulation, increasing the spatial resolution of calculations, and including more accurate treatments of aerosols, trace gas constituents, and carbon isotopes. We will improve predictive accuracy, to be validated by very sensitive new tests of climate change parameters. In addition, we are combining expertise in geophysical and atmospheric simulation to develop predictive models of regional-scale hydrological processes and of the transport and dispersion of hazardous materials. Livermore models are used for operational response to weather-related incidents and for natural resource management. These capabilities complement our National Atmospheric Release Advisory Center, a source of real-time emergency predictions worldwide if radioactive or chemical materials are released into the atmosphere.

- Multiscale Atmospheric Prediction. With Livermore's increasingly powerful computers, we will improve the spatial resolution, physics fidelity, and predictive accuracy of both our global and regional models. We will explore linking these models with one another and with data flows from satellites and other distributed measurement systems to establish a powerful operational capability and research tool for both military and civilian applications. This multiscale atmospheric prediction and assessment capability will permit effective responses to natural and manmade hazards and changes. The goal is to apply this comprehensive modeling system to anticipate, assess, and manage natural or deliberate threats to the health, safety, sustainability, and security of the U.S. environment.

\section{NUCLEAR MATERIALS STEWARDSHIP}

The Laboratory can serve as an effective national technical resource in the production, use, and disposition of nuclear materials. Many continuing activities in the Department of Energy involve nuclear materials because of its responsibility for the storage and ultimate disposition of U.S. spent reactor fuel and other nuclear wastes. Livermore's broad foundation of nuclear expertise and capabilities will help the Department to develop safe, secure, efficient, and environmentally responsible methods for all nuclear operations.

As a natural outgrowth of national security activities, much of Livermore's research involves nuclear science and nuclear materials. Major efforts include the safe and secure disposition of Cold War-legacy nuclear materials, commercialization of uranium laser isotope separation, and projects to improve nuclear systems safety. We are also working on the development of a consistent, science-based regimen for the categorization, risk assessment, and management of nuclear materials. We will provide expertise, analysis, and technologies to help the Department develop a comprehensive program for stewardship of nuclear materials.

- Yucca Mountain Repository Assessment and Implementation. The country faces a unique technical, institutional, and political challenge in the management and ultimate disposition of highlevel nuclear waste. Livermore can contribute to the success of the program by providing an integrated simulation and analysis of repository designs and performance and plans for optimum licensing, loading, and monitoring. 


\section{The Human Genome \\ Project is creating \\ ADVANCING BIOSCIENCES TO IMPROVE HUMAN HEALTH}

material resources,

technologies, and

information to set the

stage for dramatic

advances in the next

century.

Livermore is part of an accelerating revolution for this revolution was laid in the 1980 s with a shift of the national research strategy toward large-scale, complex projects, notably the Human Genome Project. This project, in which

Livermore is a significant participant, is creating in biology and biotechnology. The groundwork material resources, technologies, and information to set the stage for dramatic advances in the next century. We developed breakthrough technological tools that have enabled program successmethods for high-speed sorting of individual chromosomes and for measuring distances between DNA markers. Livermore is collaborating with Lawrence Berkeley and Los Alamos national laboratories in the Department of Energy's Joint Genome Institute.

The marriage of engineering and science that occurs at Livermore greatly strengthens the Laboratory's bioscience research and enables important advances in biotechnology. Conversely, Laboratory bioscientists make significant contributions to national security activities and other major programs. For example, we are developing detection technologies to monitor and characterize biological weapon proliferation activities and to respond in the event of an emergency.

Livermore's bioscience program grew out of a long-standing biomedical research mission to

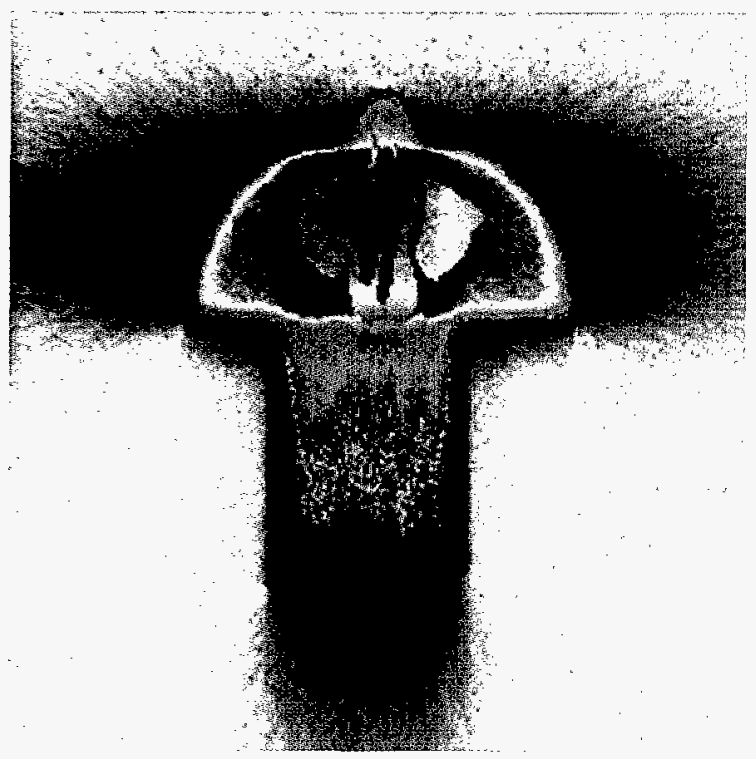

identify and characterize the effects of ionizing radiation on human health, which led to the development of sensitive instrumentation for genomics research.

For many years, most of the program's funding came from the Department of Energy's Office of Health and Environmental Research; now about half of the funding comes from other sources such as the National Institutes of Health. Because bioscience is a very cost-competitive field, the program will greatly benefit (as will many other programs) from steps the Laboratory is taking to reduce the cost of doing business and to find new ways to facilitate interactions with industrial partners.

- Genomics. The goal is to use genomics information to enhance our nation's security, preserve our environment, and ensure a better quality of life. In the course of developing a veryhigh-resolution map of human chromosome 19 , we created unique research capabilities that make it relatively straightforward to isolate and characterize genes of interest in almost any species. Livermore's emphasis on gene discovery and highthroughput DNA sequencing will greatly benefit from our development of robotics technologies that minimize repetitive tasks and reduce costs. In the process of generating highly accurate DNA sequences, we will maintain, characterize, and analyze a collection of genes. Livermore will provide for public access to these data and analysis tools.

- Disease Susceptibility and Prevention. We are examining the relationship between an individual's genes and health risks from adverse environments. This research includes efforts to identify genes that determine individual susceptibility, to understand how the proteins that these genes encode might be involved in the disease process, and, finally, to estimate risk for disease based upon an individual's genetic constitution and environmental exposure. These activities will draw upon Livermore's expertise in molecular genetics, as well as bioscience and bioengineering.
A cross section of an absorbed radiation dose for treating cancer of the brain is shown after calculation by the Laboratory's Peregrine radiation planning system, which will improve cancer treatment. 
- Health Care and Medical Biotechnology. The goal is to develop cost-effective healthcare technologies with high impact on disease prevention, diagnosis, and treatment. Livermore's Center for Healthcare Technologies serves as a coordinating and marketing focal point for projects that combine the Laboratory's expertise in sensors, imaging, computational physics, informatics, microfabrication, and lasers with university and industry knowledge in biomedicine. For example, Livermore is developing novel methods and surgical tools for the treatment of stroke, and we are adapting physics simulation capabilities into a unique planning tool (Peregrine) for radiation treatment of cancer. More than 350,000 Americans each year who are diagnosed with a "curable" form of the disease could benefit. We will explore the establishment of a molecular medicine program to couple our strengths in molecular and cellular biology to the development of diagnostic instruments and ultimately to clinical treatment.

\section{PURSUING BREAKTHROUGHS IN FUNDAMENTAL SCIENCES AND APPLIED TECHNOLOGY}

One of Secretary of Energy Federico Peña's four key priorities is to ensure that the U.S. maintains its world leadership in science and technology. It is widely recognized that the nation's advances of fundamental knowledge and innovation provide the U.S. an advantage in an increasingly competitive world.

The pursuit of fundamental science and the advance of applied technology go hand in hand at Livermore. State-of-the-art applied technology is used to advance fundamental science, most frequently in areas pertinent to the Laboratory's major missions and often using Laboratory Directed Research and Development as an initial source of funding. For example, we have successfully demonstrated that laser guide star adaptive optics can correct for atmospheric turbulence.
Livermore's development and installation of a laser guide star system on the 10-meter-diameter Keck II Telescope on Mauna Kea, Hawaii, will significantly improve the quality of its images.

The Laboratory's scientific advances-and technologies developed in the pursuit of fundamental science-have important spin-off and spin-back applications. The laser guide star technology is helping us in the design of the National Ignition Facility. The discovery of fluid metallic hydrogen-a new state of mattercontributes to planetary science and generates new knowledge about the properties of hydrogen needed for Laboratory programs. Livermore's petawatt laser enables physics experiments never before possible and also has precision cutting applications for advanced manufacturing in stockpile management and broader applications. Technologies developed to build the petawatt laser are enabling revolutionary advances in flatpanel displays for computers and television sets.

-Astrophysics and Space Science. In partnership with many other scientific institutions, we will continue to make important advancements in astrophysics and space science through application of the Laboratory's special expertise in highenergy-density physics, nuclear fusion, and scientific computing. As we improve materialproperty models and simulation codes in support of stockpile stewardship, we will make discoveries about stellar evolution and other high-energy astrophysics processes. Livermore also makes important advances in instrumentation, as

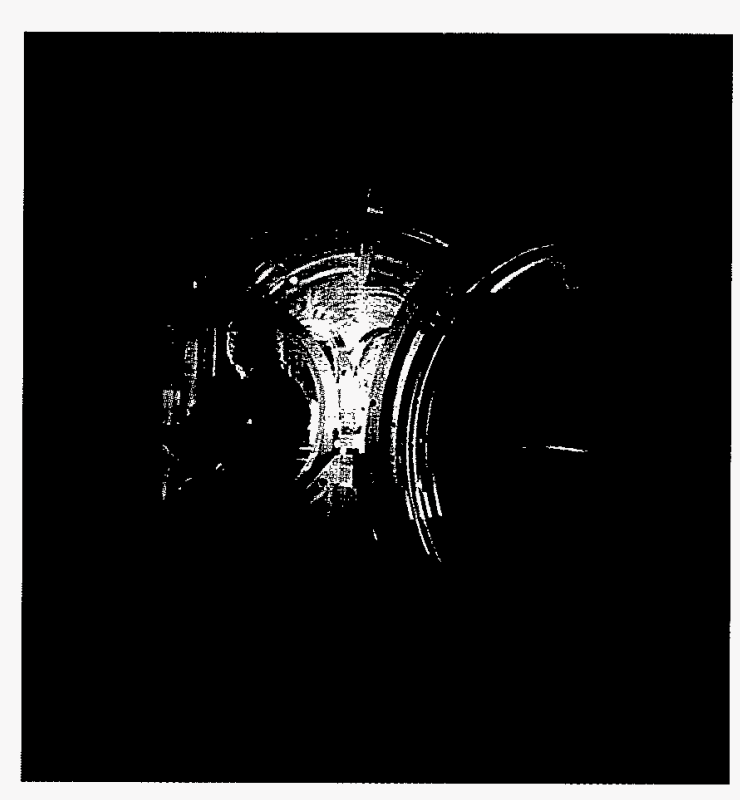

A technician adjusts a diagnostic lens in Livermore's ultrashortpulse petawatt laser. 


The Laboratory's
scientific advances-
and technologies
developed in the
pursuit of fundamen-
tal science-have
important spin-off and
spin-back applications.

spin-back applications. demonstrated by the development of sensors for the Clementine satellite, which mapped the entire surface of the Moon at resolutions never before attained. This sensor technology is leading to other advances, such as the development of a revolutionary camera system and its use to discover massively compact halo objects (MACHOs).

- Accelerator Technology. We will continue to make strong contributions to national accelerator development programs, capitalizing on the way our physicists and engineers work together to solve problems in accelerator design, technology, and manufacturing. Livermore is part of the threelaboratory collaboration building the B-Factory at the Stanford Linear Accelerator Center, an effort at the forefront of high-energy physics research. We are also collaborating on the development of the Next Linear Collider. Livermore's accelerator expertise has important national security applications for the development of Accelerator Production of Tritium and the Advanced Hydrotest Facility.

- Micro-electronics and Opto-electronics. The Laboratory's strengths in micro-electronics and opto-electronics will help meet the demands for enhanced surveillance of aging nuclear weapons as well as for advanced diagnostics and precision target fabrication in the inertial confinement fusion program. Expertise in thin-film processing and microfabrication technology has many applications in lithography, semiconductor processing and process modeling, electronics packaging, communication and computing systems, and biotechnology. We will pursue, in partnership with U.S. industry, the development of lithography technologies that are pivotal in producing the next generation of integrated circuits.

- Advanced Materials. In support of Laboratory programs, we engineer novel materials at the atomic or near-atomic levels and carry development of these materials to the stage where they can be readily manufactured. Aerogels and nanoengineered multilayer materials are examples of Livermore advances that have tremendous implications for new products and future Laboratory programs. Advances include highly efficient energy-storage and energy-generation components, ultra-lightweight structural materials, tailored coatings, and novel electronic, magnetic, and optical materials.

- Laser Science and Technology. The Laboratory has unmatched capabilities in high-energy and high-power, solid-state lasers. We will apply this expertise to meet critical needs in national security, energy security, and environmental applications. We will continue to lead the world in studying the interaction of intense radiation with matter. Livermore will expand collaborations with industry and other partners to identify laser and electro-optics technologies that can be developed and transferred to the private sector.
Livermore precision machining experts produce specialized radiofrequency cavities for the B-Factory at the Stanford Linear Accelerator Center. It will be used to create pairs of $B$ mesons and anti-B mesons and study the origin of matter in the universe.

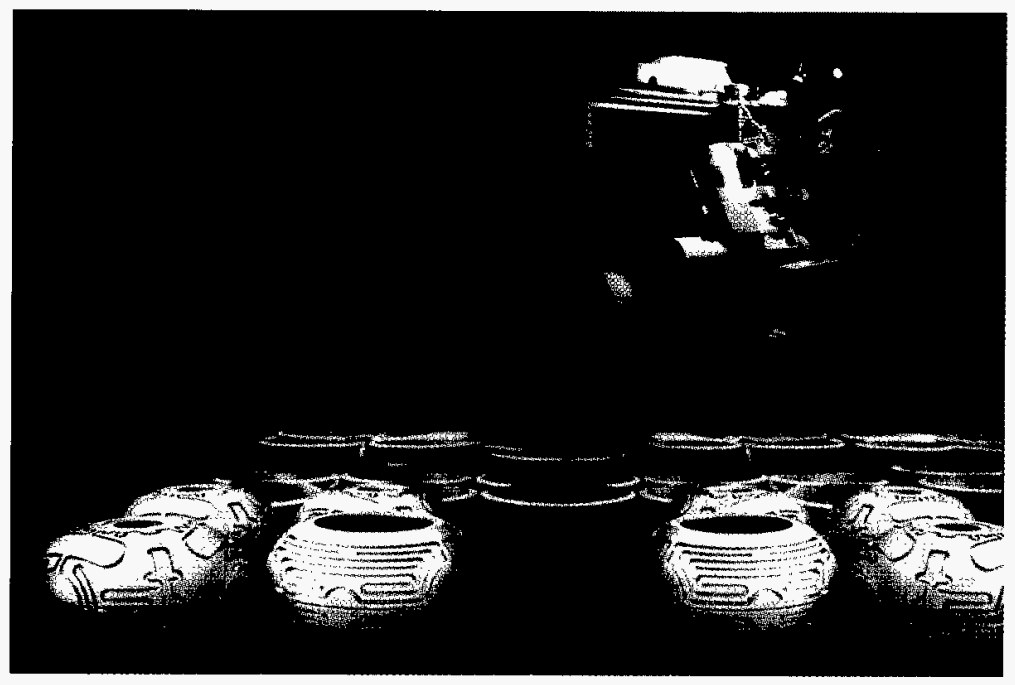




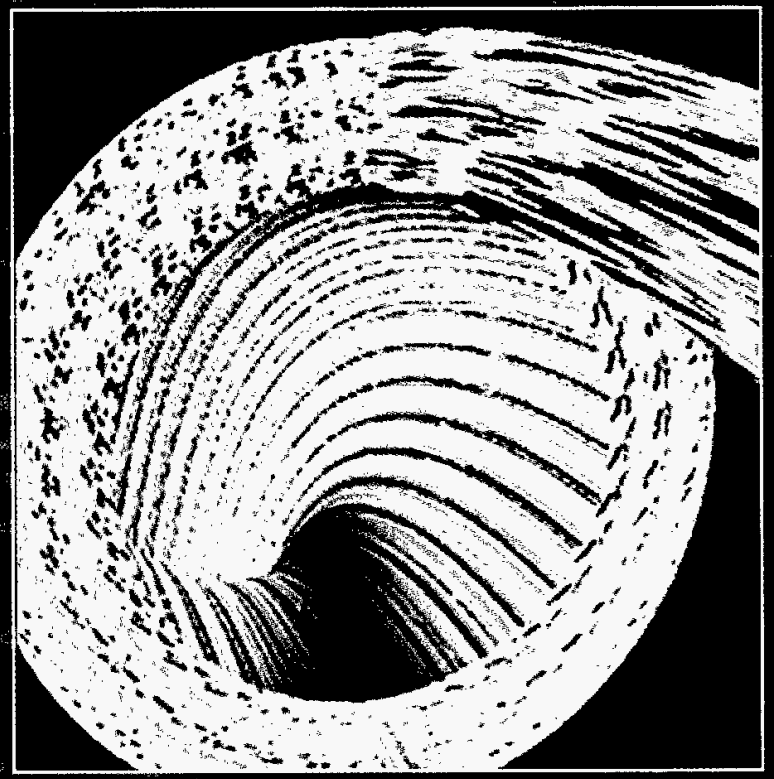




\section{MISSION-DIRECTED SCIENCE AND TECHNOLOGY}

ivermore's multidisciplinary

teams excel in conducting large-scale

research and development aimed

at solving important

national problems.
Stable mission responsibilities provide the

Laboratory with considerable program continuity, enable an institutional accumulation of knowledge and expertise, and foster investments in new facilities and capabilities. We have developed wide-ranging capabilities in applied science and technology and unique expertise in selected areas. Livermore's programmatic successes stem from our focus on problem solving, the strength of the Laboratory's science and technology, the quality of our staff, and the use of effective partnerships to enhance the Laboratory's capabilities and provide a means for sharing technologies with others. Success demands effective technical project management to ensure that deadlines and budgets are met and that the product meets or exceeds the customer's expectations.

\section{A NATIONAL RESOURCE OF SCIENCE AND TECHNOLOGY}

The Laboratory is a national resource of science and technology with an extensive science and technology base and many specialized centers of excellence. Livermore provides leadership in several broad research areas that are central to the Laboratory's missions.

\section{An Extensive Science and Technology Base}

Livermore programs are supported by a large technical base consisting of more than 1,000 Ph.D. scientists and engineers. A significant portion of the scientific staff is organized into "discipline" directorates-Chemistry and Materials Science, Computations, Engineering, and Physics-and many of these people are matrixed, or assigned, to specific programs. Use of the matrix system fosters efficient transfer of technical knowledge among programs, enables staff members to develop a wide-ranging set of skills and knowledge, and infuses projects with diverse ideas for solutions. As a result, the Laboratory has the ability to seize program opportunities, the agility to react quickly to technical surprises, and the flexibility to respond to programmatic changes.

- Assessing and Ensuring the Health of the Science and Technology Base. The ability to sustain an excellent base of science and technology is fundamentally important to the Laboratory's current and future programs. Significant changes are under way at Livermore in the way we assess the health of the science and technology base and make strategic investments to maintain its vitality. Ongoing improvements in the method for accounting for internal costs are enabling Laboratory managers to better monitor internal investments and rebalance them, as necessary, to ensure a healthy technical base and effective use of the matrix system. We will be implementing new approaches to assessing the quality of the Laboratory's core capabilities in science and technology. We plan to benchmark Livermore's work against the highest national and international standards, and we will use these assessments to guide science and technology investment decisions.

\section{Specialized Centers of Excellence}

Many specialized centers of excellence exist at Livermore. Because of our overall size, the need for technologies and capabilities that do not exist elsewhere, and the fact that essential elements of our national security mission are classified, much of the necessary expertise to support programs resides within the Laboratory. For example, we have capabilities to develop state-of-the-art instrumentation for detecting, measuring, and analyzing a wide range of physical events. We also have expertise to support innovative efforts in advanced materials, precision engineering, microfabrication, nondestructive evaluation, complex-system control and automation, and chemical, biological, and photon processes. 


\section{Leadership in Research Areas Central to Our Missions}

The Laboratory's many research and development accomplishments demonstrate Livermore's leadership in several broad research areas.

- High-Energy-Density Physics and Nuclear Science and Technology. For over 45 years, the Laboratory has demonstrated excellence in science and technology directed at the development of nuclear weapons and the harnessing of thermonuclear and fission energy for civilian power. We have broad expertise in nuclear science and technology as well as exceptional capabilities for investigating the properties of matter at extreme conditions (up to stellar temperatures and pressures) and the interaction of matter with intense radiation. This expertise will remain crucial for our national security programs. It will also be applied to develop innovative techniques for environmental cleanup, assist the Department of Energy in the stewardship of nuclear materials, and advance fundamental science in many areas.

-Advanced Lasers and Electro-Optics. Livermore is the pre-eminent laser science and technology laboratory in the world. We are strongly focused on two high-priority effortsmeeting design and construction goals for the National Ignition Facility and successfully completing the transfer of uranium atomic vapor laser isotope separation to the private sector. We are also applying the Laboratory's expertise in lasers and electro-optics to meet other national needs, contribute to the competitiveness of U.S. industry, and address issues in basic science.
- High-Performance Scientific Computing. Over the next decade, we will be acquiring successively more powerful computers with the goal of achieving increases in computational speed and data capacity by a factor of 100,000 . By December 1999, we expect to have a 10-teraflops computer (10 million megaflops), capable of performing calculations in 5 minutes that currently would take 40 days to complete. While meeting the Laboratory's commitments to national security programs, we are making internal investments to ensure that all major Livermore programs have access to these advanced computing capabilities. They offer the potential of revolutionizing scientific discovery and leading to unprecedented levels of understanding in climate and weather modeling, environmental studies, the design of new materials, and many areas of physics.

\section{AN OUTSTANDING WORKFORCE}

The Laboratory's principal asset is its quality workforce. We will seek highly talented, productive, motivated, flexible people who are committed to Laboratory goals and reflective of the diversity of California and the nation. Our recruitment, reward, and advancement decisions will be based on contribution to Livermore's success. We will recognize and reward both team excellence and individual accomplishments. We expect all employees to take pride in and responsibility for their work, improve their skills, and continue their professional growth.
Expertise in advanced lasers and associated technologies, necessary for the National Ignition Facility and other major projects for national security, provides program opportunities in laser isotope separation, inertial confinement fusion, advanced lithography, and other diverse applications.

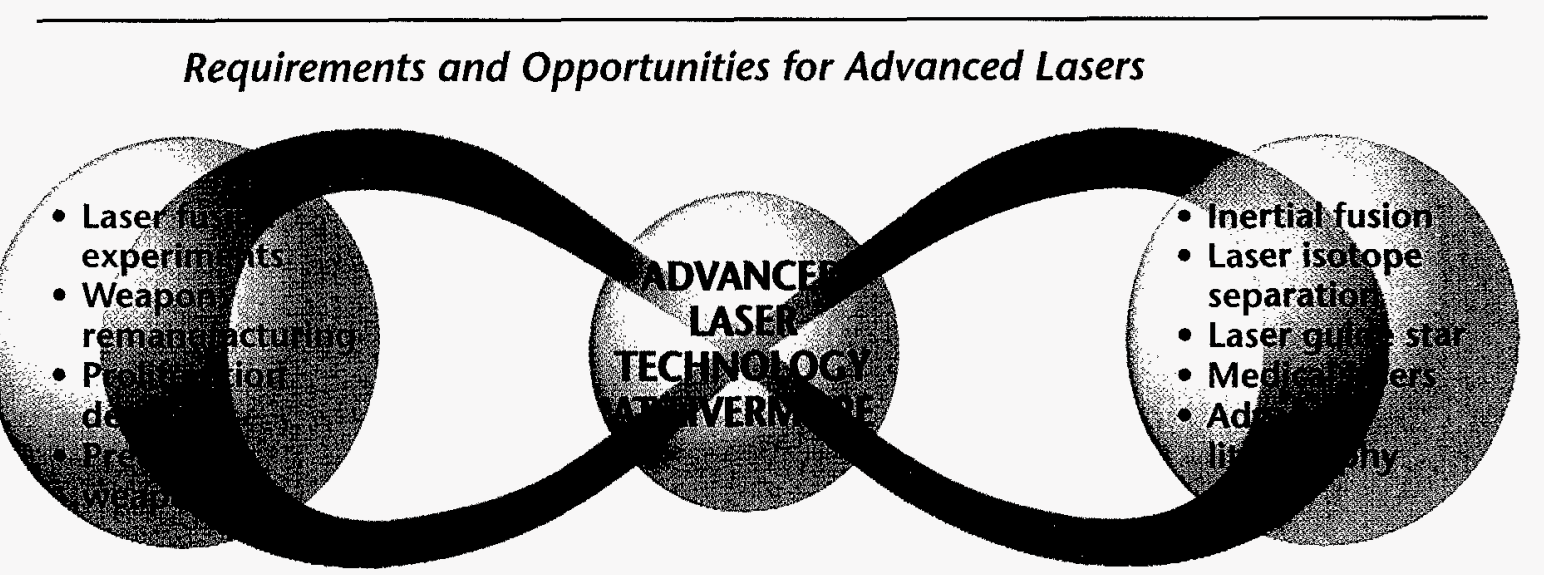


Challenging scientific programs, world-class research facilities, and a collegial environment are critical to attracting and retaining an outstanding workforce.
- Creative Research Opportunities for Scientists and Engineers. Challenging scientific programs, world-class research facilities, and a collegial environment are critical to attracting and retaining an outstanding workforce. The Laboratory will pursue state-of-the-art science and engineering to achieve breakthrough accomplishments in all of its major programs. The diversity of opportunities that exist at Livermore offers the technical staff many options for career changes and career growth.

- Valuing Breakthrough Achievements. The Laboratory greatly values and will recognize and reward outstanding scientific and technical achievements by individuals and research teams. Breakthrough accomplishments are critical to the success of Livermore's programs and provide the foundation for future programs to meet national needs. Frequently such achievements lead to international honors such as E. O. Lawrence Awards, R\&D 100 Awards, and other distinguished prizes and awards presented by professional societies.

- A Part of the University of California. The Laboratory's association with the University of California will continue to make a significant difference in the decision of people to work at Livermore. The strong bond between Livermore and the University nurtures an atmosphere at the Laboratory in which independent views and technical honesty are treated as core values, and it has led to an array of scientific and technical associations that would not have been achievable otherwise. We place great importance on continuing and further strengthening this relationship.

\section{PARTNERSHIPS THAT CREATE NEW CAPABILITIES}

Partnering has been important at the Laboratory ever since Livermore's establishment as part of the University of California and the early days of supercomputer development to meet the needs of the weapons program. It will play an even more significant role in the future. Working with industry, academia, and other partners strengthens and adds vitality to the Laboratory. Partnerships and collaborations help us accomplish our programmatic goals more efficiently and cost effectively. They reinforce our strengths by helping us excel at what we do best. And they provide us capabilities not existing at the Laboratory. We also work with others to share expertise or make available research capabilities. We strive to be known as a center for science and technology and will provide wide access to the Laboratory's experimental facilities and staff.

Partnering activities will span a wide rangefrom very-large-scale strategic alliances to licensing of individual technologies, academic research, and support for the small business community. Partnerships will be woven throughout the fabric of Livermore's major programs. The National Ignition Facility is a major collaboration with Los Alamos, Sandia, and the University of Rochester, as well as the French CEA-Division Applications Militaire and the British AWE-Ministry of Defence. Over $75 \%$ of the total funding for construction of the NIF will go to U.S. companies, including high-technology firms producing optical components. The NIF will support cuttingedge collaborative research in astrophysics, plasma physics, and many other fields.

As part of the Accelerated Strategic Computing Initiative (ASCI), Livermore, Los Alamos, and Sandia will be purchasing from U.S. industry the most cost-effective means for "conducting" a large number of complex experiments. Confidence in modeling results depends on careful validation through actual experiments. The use of simulations and experiments is mutually reinforcing. 


We strive to be known
as a center for science
and technology
and will provide
wide access to the
Laboratory's
experimental facilities
and staff.

increasingly capable supercomputers. ASCI is a partnership involving the three laboratories, industry, and academia to drive the advancement and refine these prototype machines, which will help ready them for the wider marketplace. At Livermore, we are working closely with IBM and took delivery in 1996 of the first elements of IBM's most capable supercomputer (the 512-node SP). Additional elements to increase the computer's capabilities are planned for delivery by the end of 1998 , leading to a machine with an operating speed of 3 teraflops - about 300 times faster than our previous best computer.

\section{Partnerships with Industry}

We anticipate that the Laboratory's partnerships and alliances with industry will continue to grow. For example, we will apply Livermore's expertise in microfabrication and micro-electronics to develop new lithography capabilities for the production of advanced computer chips, which will lead to improvements in the Laboratory's computing capabilities. This collaborative research and development project will involve Lawrence Berkeley and Sandia national laboratories together with an Intel-led consortium of micro-electronics companies. Livermore will also be part of the virtual national laboratory, a Department of Energy partnership to address critical technology needs for the Department and U.S. industry. We will form partnerships through a variety of mechanisms such as memoranda of agreement, cooperative research and development agreements, non-federal Work for Others agreements, cost-shared procurements, licenses, and software collaborations.

- Licensing Agreements. We will collaborate with industry through the licensing of Livermoredeveloped technologies, such as our revolutionary micropower impulse radar-the so-called radar on a chip-which has many potential applications.

- Cooperative Research and Development. We will work with U.S. industry through a variety of cooperative research and development arrangements in which intellectual property rights are
Livermore's laser guide star adaptive optics system can improve the resolution of ground-based telescopes by more than tenfold. negotiated. Future growth in this area will depend on the technical success and businesslike management within the Laboratory of current cooperative activities. We will examine and implement innovative ways to work with industry, such as the establishment of Laboratory-affiliated not-forprofit companies or foundations. These arrangements will help support our technology base, provide even greater community outreach and exposure to modern business practices, assist in the recruitment and retention of a quality workforce, and lead to important "spin-backs" to Laboratory programs.

\section{Collaborations with Academia}

We will continue to increase our many formal and informal collaborations with the University of California campuses and other academic institutions. The University of California at Davis Department of Applied Science is located on the Livermore site. In addition, we are home to several University of California scientific research institutes and other centers that support hundreds of ongoing projects with faculty, postdoctoral fellows, and graduate students. By making Livermore's major research facilities and staff more accessible to the academic community, we gain access to a larger pool of talent, which helps us accomplish our programmatic goals while providing valuable opportunities to visiting researchers. We also will help to train the nation's next generation of scientists and engineers through our science and technology education outreach programs.

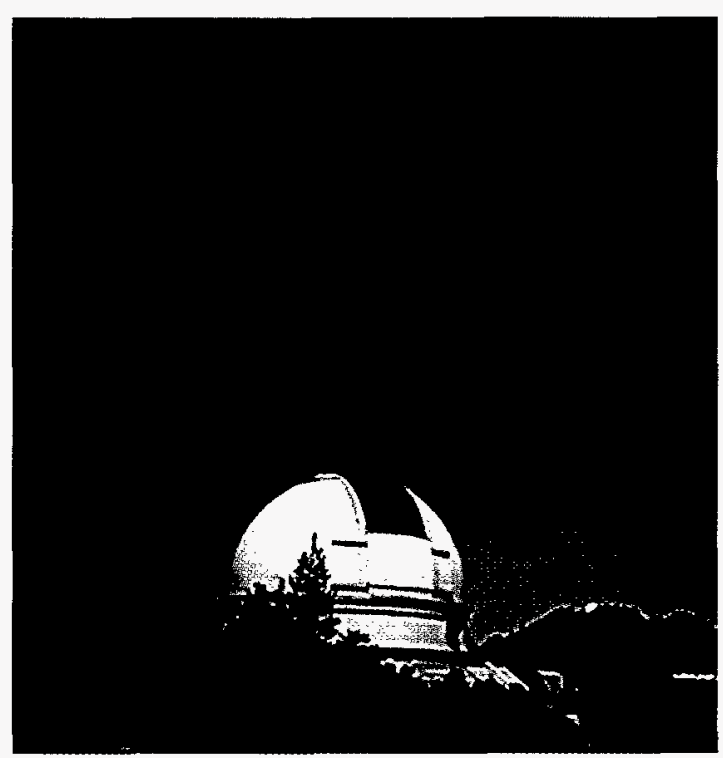




\section{Livermore's goal is to}

serve and be valued as

an intellectual asset

and contributing

neighbor in the San

Francisco Bay Area

and California.

\section{Teamwork with Other Laboratories}

We will work with other national laboratories-both in the U.S. and abroad as appropriate- to coordinate and integrate programmatic efforts to provide the best scientific and technical capabilities for the dollars invested. Livermore's collaborative activities are increasing through participation in integrated national programs, such as the Stockpile Stewardship and Management Program and the Joint Genome Institute. Collaborations will include the design, construction, and shared use of major research facilities such as the National Ignition Facility and the B-Factory at the Stanford Linear Accelerator Center. Critical success factors will be effective high-level Department of Energy leadership, well-defined program goals and deliverables, complementary capabilities among the national laboratories, confidence in each other's commitment and performance, and a healthy competition of ideas within a collaborative framework.

\section{A Home in California}

California is a special place. We share in its diversity, its emphasis on high technology, its global outlook, and its focus on the future. We also have common science and technology interestswater conservation, seismic safety, natural resource management, energy use and transportation, environmental protection, and science education. Many of these same complex issues are also challenging the nation. We will apply Livermore's expertise in these areas to provide the technical basis to support effective decisions.

Livermore's goal is to serve and be valued as an intellectual asset and contributing neighbor in the San Francisco Bay Area and California. We must assure honest, open interactions with the communities around us-we want them to be proud that we are here.

\section{Principal Research Centers and Facilities at Livermore}

Atomic Vapor Laser Isotope Separation Facility-advanced capability for industrial-scale research on uranium processing.

Center for Accelerator Mass Spectrometry-most versatile spectrometry capability in the world.

Chemistry and Materials Science Environmental Services Laboratory-wide-ranging capability to provide chemical and radiochemical characterization of environmental samples.

Conflict Simulation Laboratory-state-of-the-art, interactive, entity-level conflict simulation.

Electron Beam Ion Trap Facility-first achievement of totally ionized uranium without use of a high-energy accelerator.

Flash X-Ray Facility-currently the most capable hydrodynamic testing facility in the world.

Forensic Science Center-world leadership in development of new forensic capabilities and instrumentation.

Genome Center-home of world's largest collection of cloned genes and the most detailed map of a human chromosome.

High Explosives Applications Facility-world's most modern high-explosives research facility.

International Assessments Center-national resource for evaluations of foreign weapons programs.

Large Optics Diamond Turning Machine--world's most accurate machine tool for fabricating large metal optical parts.

Microtechnology Center-world leader in laser-based microtechnology development.

National Atmospheric Release Advisory Center-for real-time emergency predictions for hazardous substance releases.

Nova Laser-the world's primary research tool for inertial confinement fusion.

Petawatt Laser-the world's most powerful laser.

Plutonium Facility-modern facility for nuclear materials research and testing.

Positron Microscope-world's most intense pulsed proton beam for studying material defects.

Secure and Open Computing Facilities-the Laboratory's supercomputers and testbed for hardware and software development.

Superconducting Magnet Test Facility-unique development testing facility for large superconducting magnets.

Two-Stage Gas Guns-first achievement of metallic hydrogen. 


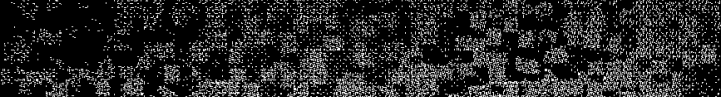

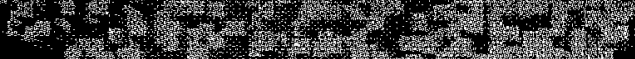

3

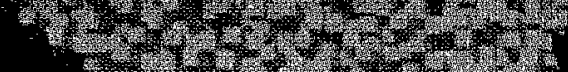

1013)

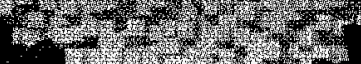

s.t.

$-2 y^{2}+y^{2}$

tr.

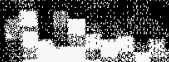
$4 x_{2}+4$ (1)

\section{4}

(4)

th

(3)
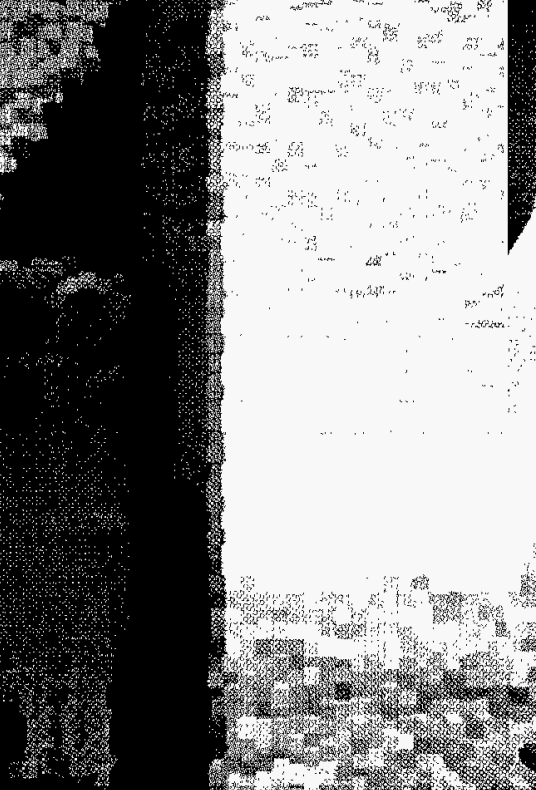

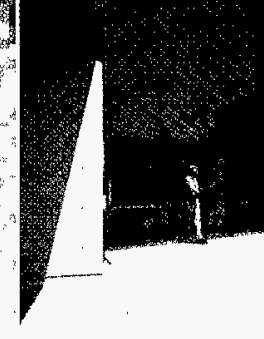

is tx, 1 ) 3. 27

竝

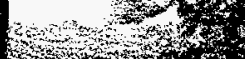
3
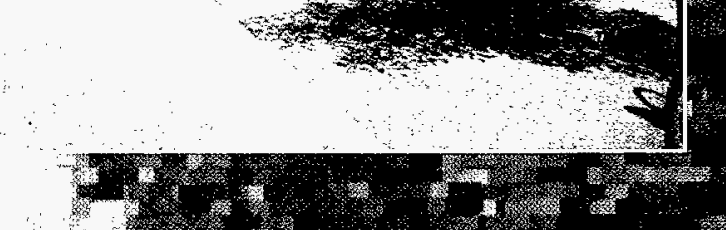

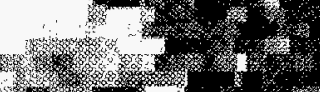
is 1 (

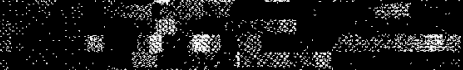

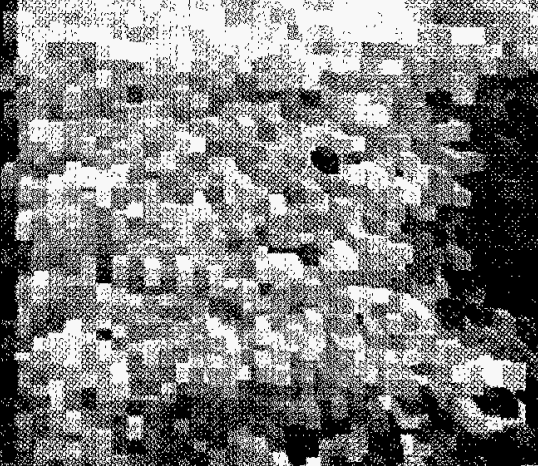

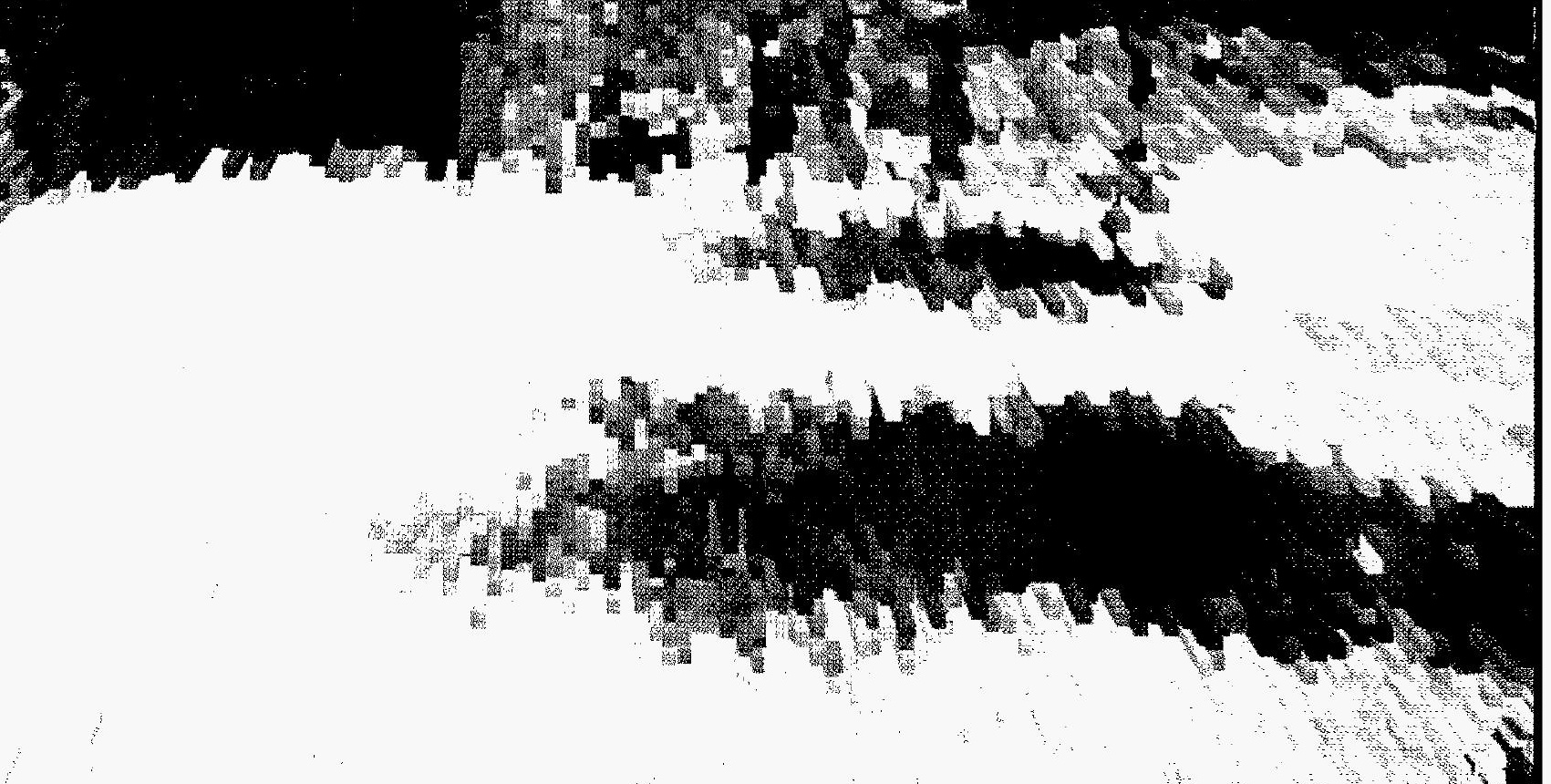


Cafe and efficient operations, sound business practices, and attention to the Laboratory's valuable

resources make

possible

Livermore's

technical

achievements.
High-quality, cost-effective operations provide essential support to the Laboratory's mission. They facilitate a high level of technical accomplishment while assuring to sponsors sound business practices and compliance with applicable regulations.

\section{SAFETY FIRST}

Safety is the most important day-to-day consideration in operations. The Laboratory will provide every employee and the community with a safe and healthy environment in which to work and live. We are committed to accomplishing Laboratory mission objectives while protecting employees, the public, and the environment. To achieve this commitment, all Livermore employees must be accountable for their own safety and that of their coworkers and the general publicand for the protection of the environment. We must be particularly safety conscious at Livermore because we take on many large projects with high-technology systems. To help ensure success in these efforts, we have reorganized Laboratory operations to place a Director's Office-level focus on safety, health, and environment.

- Integrated Safety Management. We fully integrate environmental, safety, and health considerations into the research programs and operational culture of the Laboratory. Integrated safety management requires accountability at all levels of the organization, planning and design for safety at the early stages of a project to anticipate potential problems, compliance with laws and other requirements, and excellence in execution. Laboratory researchers are working with safety professionals from the Department of Energy and the Laboratory to identify hazards and establish "work smart standards" appropriate to the particular work environment. These standards will result in improved safety at lower cost.

\section{ATTENTION TO WORKFORCE NEEDS}

The quality of the technical and administrative staff of the Laboratory is the source of Livermore's strength. The Laboratory must adjust to a future in which the workforce is changing rapidly, both demographically and in terms of its approach to the work environment. We strive for a work environment in which all employees can contribute, feel valued, and support the Laboratory. The goal is a diverse employee population with the motivation, innovation, and skills needed for Livermore to excel in its mission.

- Recruitment and Retention. Challenging technical programs and world-class research facilities are important attributes of the Laboratory that will help us attract and retain outstanding scientists and engineers. However, we must be more aggressive in selected disciplines where there is significantly increased competition for the best people. We will explore new ways to attract the best people to the Laboratory, and we will provide a wide array of options (i.e., compensation, benefits, work environment, services) to retain employees. We will also strengthen ties to university departments and programs aligned with the Laboratory's research interests, including opening up prestigious new postdoctoral research opportunities.

\footnotetext{
Many modern office buildings and research facilities, such as the one shown, are situated at the Livermore site. Nearly 7,000 full-time employees work at the Laboratory in 1997.
} 
- Workforce Vitality. The Laboratory encourages employees to take seriously their responsibilities for their own career development. In support of career development, we will ensure that the Laboratory's continuing education and training programs continue to be relevant to shortand long-term goals of the Laboratory and employees' needs. We also will provide all employees access to mentoring if they so desire.

- Performance Motivation. We will explore ways to supplement the Laboratory's merit-based compensation system with means for rewarding exceptional contributions, such as the new Director's Performance Rewards. We will also continue to improve performance appraisal processes throughout the Laboratory with the goal of empowering and motivating all employees to contribute to their full potential.

- Development of Leadership Skills. Livermore's future depends on continual development of leaders who are visionary, skilled in managing and building programs, and sensitive to workforce needs. We are establishing a training program for all Laboratory managers to expand and deepen essential skills in such areas as personnel management, program leadership, finances, safety, and policy implementation.

Livermore has significantly improved its performance ratings as the Laboratory has reduced overhead costs.

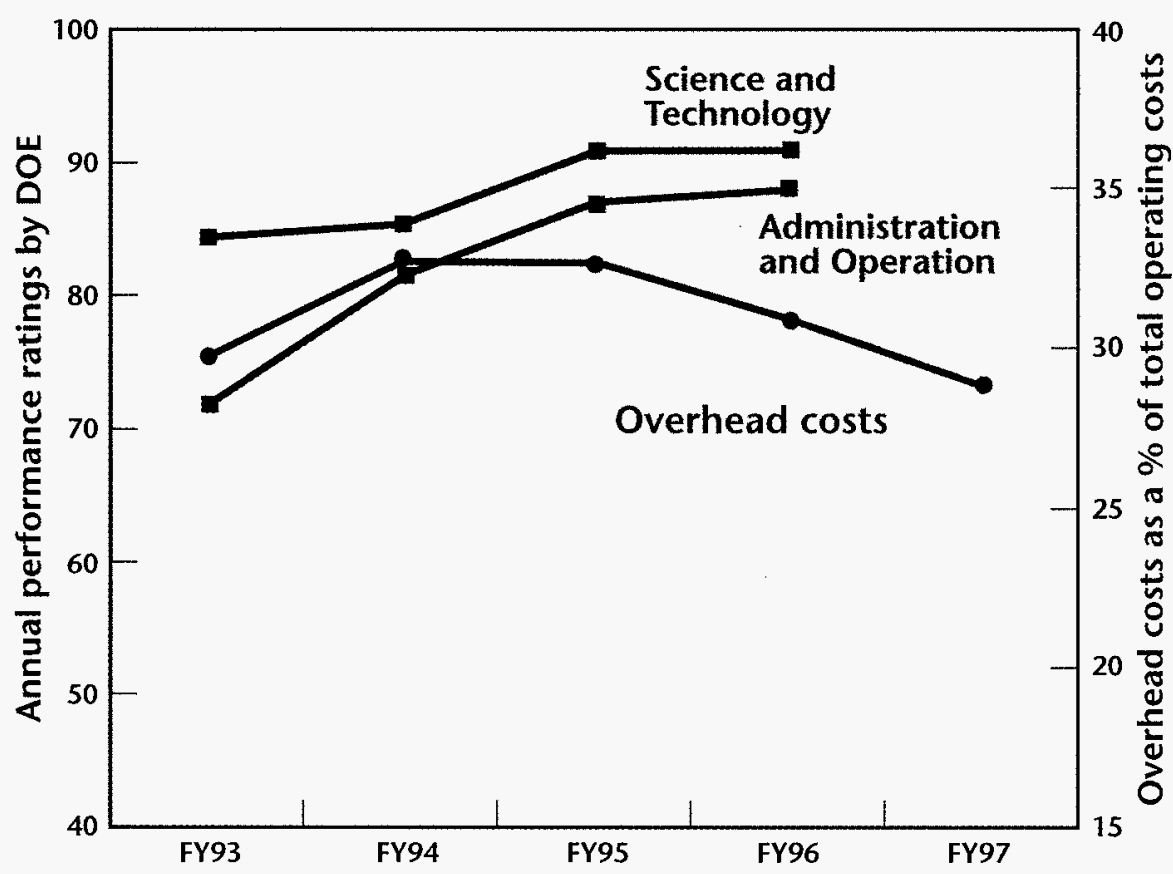

COMMITMENT TO PERFORMANCE-BASED MANAGEMENT

The three University of California laboratories are at the forefront of the Department of Energy's efforts to implement performance-based management. The University of California and the Department of Energy pioneered this management concept, as applied to government-owned institutions, in the 1992 contract for managing and operating the Livermore, Los Alamos, and Lawrence Berkeley national laboratories. Performance-based management involves an annual negotiation of performance objectives and measures, a Laboratory self-assessment against these measures, and evaluations by the Department of Energy and the University. The result is improved performance, better communication of expectations, and a closer working relationship among the Laboratory, the University, and the Department.

\section{A COST-REDUCTION STRATEGY}

Although the lowest-cost action is not always the right approach at a research and development laboratory that is pushing the state of technology, cost is an increasingly important consideration. All Laboratory programs greatly benefit from reductions in overhead costs. Concerted costcutting efforts have reduced overhead costs from nearly 33\% of the operating budget in FY 1995 to about $28 \%$ in FY 1997 as our performance ratings improved. We first revised the accounting structure at Livermore to illuminate the true cost of all overhead functions. This information enabled Laboratory management to make informed decisions to reduce costs and revealed areas that need further attention. Next, a costcutting task force conducted a comprehensive study of programmatic and operational activities. Task force recommendations led to a number of cost-cutting steps and are guiding plans for future ones. The goal is to further reduce overhead costs 


\section{Concerted cost- cutting efforts have reduced overhead costs from nearly $33 \%$ of the operating budget in FY 1995 to about 28\% in FY 1997 as our performance ratings improved.}

to $25 \%$ of the Laboratory's budget by 1999 . To date, major cost-cutting steps have attained a \$30-million-per-year increase in the buying power of the Laboratory's programs.

- Centralization and Standardization of Information Systems. The goal is to have an electronic information system infrastructure that operates flawlessly and transparently across the Laboratory to connect people to information so that they can accomplish the Laboratory's business as efficiently as possible. Increasingly, the Laboratory is using the Internet to reduce the cost and increase the efficiency of internal communications. In addition, we are standardizing desktop computer systems, software, and databases at Livermore, and we are consolidating support activities for desktop systems and computer networks under the leadership of a Chief Information Officer.

- Matching the Workforce to the Work. In FY 1996, Livermore undertook a workforce restructuring to reshape the staff profile and assure a mix of skills appropriate for current and near-term future work. The restructuring reduced the staff by more than 500 employees through a voluntary separation program. We are increasing the fraction of the workforce that engages in programmatic work. On a semi-annual basis, we will update the Laboratory's Workforce Plan to project future workforce needs and identify institutional workforce issues that merit attention.

- Efficient Business Management Practices. The Laboratory is achieving significant performance improvements through adoption of "best business practices" as a substitute for "federal norms." We are making a significant move toward the commercial norm on the services side of the Laboratory, especially in the business organizations, by taking an aggressive look at cost-versusbenefit tradeoffs. Every operations areaincluding operations activities within technical organizations-is a candidate for management practices improvement to reduce costs and increase efficiencies. Outsourcing will be an option that is considered in all future business structure decisions. The goal is for the
Laboratory's underlying infrastructure to operate nearly transparently so that technical organizations will be able to obtain needed services quickly and efficiently.

\section{MAINTAINING LABORATORY FACILITIES}

We have completed a Comprehensive Site Development Plan that documents the current state of and near-term projections for the Laboratory's facilities and associated infrastructure. Although the Laboratory has some very modern office and research facilities, over half the buildings are more than 30 years old. Laboratory management has identified maintenance of a vital facility infrastructure as a critical factor in ensuring the future success of the Laboratory. Aggressive measures will be taken to rid the Laboratory of unused and substandard facilities, further reducing institutional overhead expenses.

- Institutional Facilities Manager. An institutional facilities manager was recently appointed to develop and implement a long-term strategy and an associated set of priorities for managing facility investments. This effort will involve close collaboration with other senior Laboratory managers to meet and balance programmatic requirements and site development goals. The strategy will include the development of initiatives to revitalize core facilities, reduce space (together with consolidating and mothballing or demolishing surplus buildings), and more effectively use existing building maintenance funds through prioritization, outsourcing, and productivity improvements. 


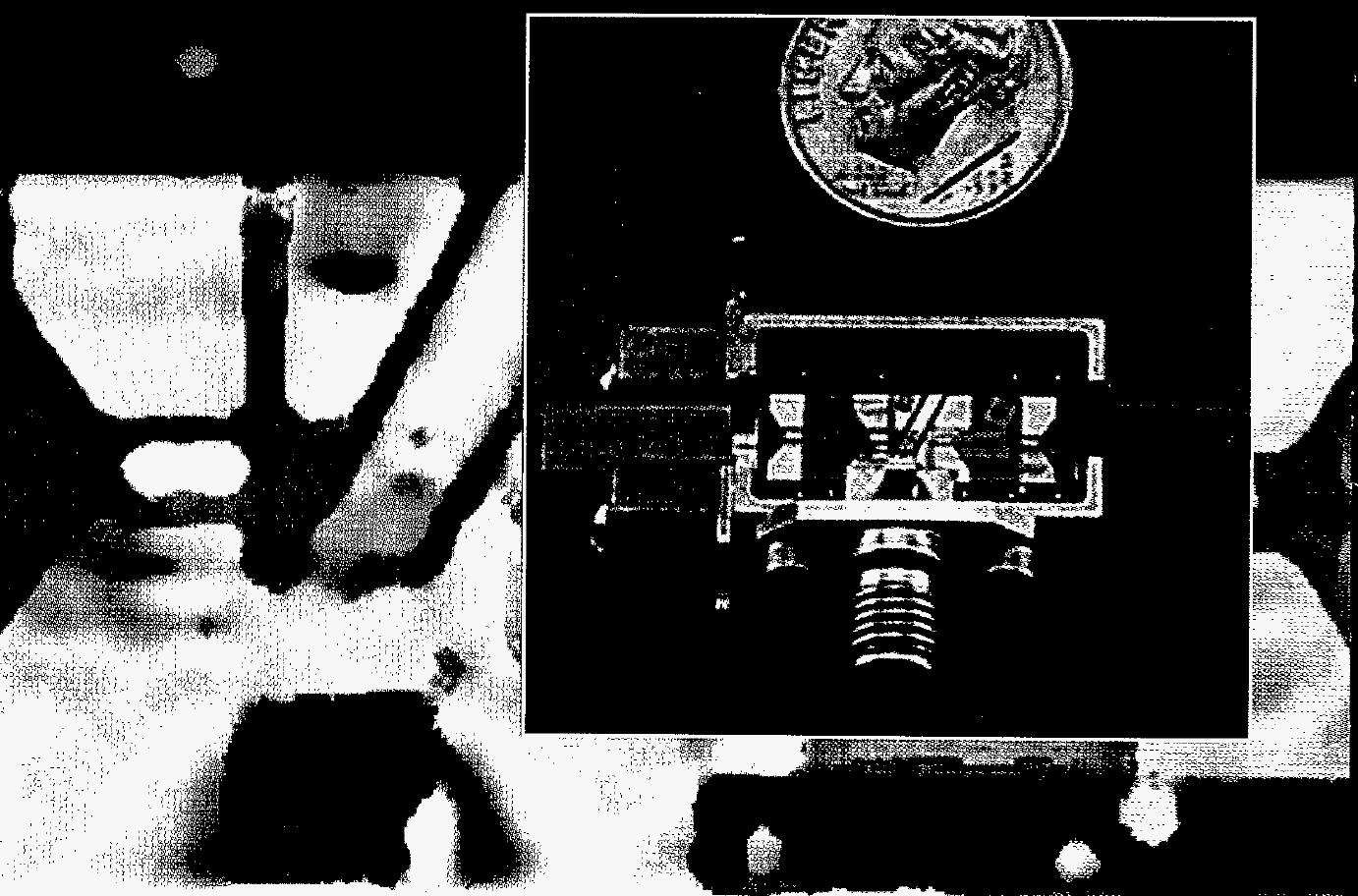

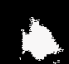

器
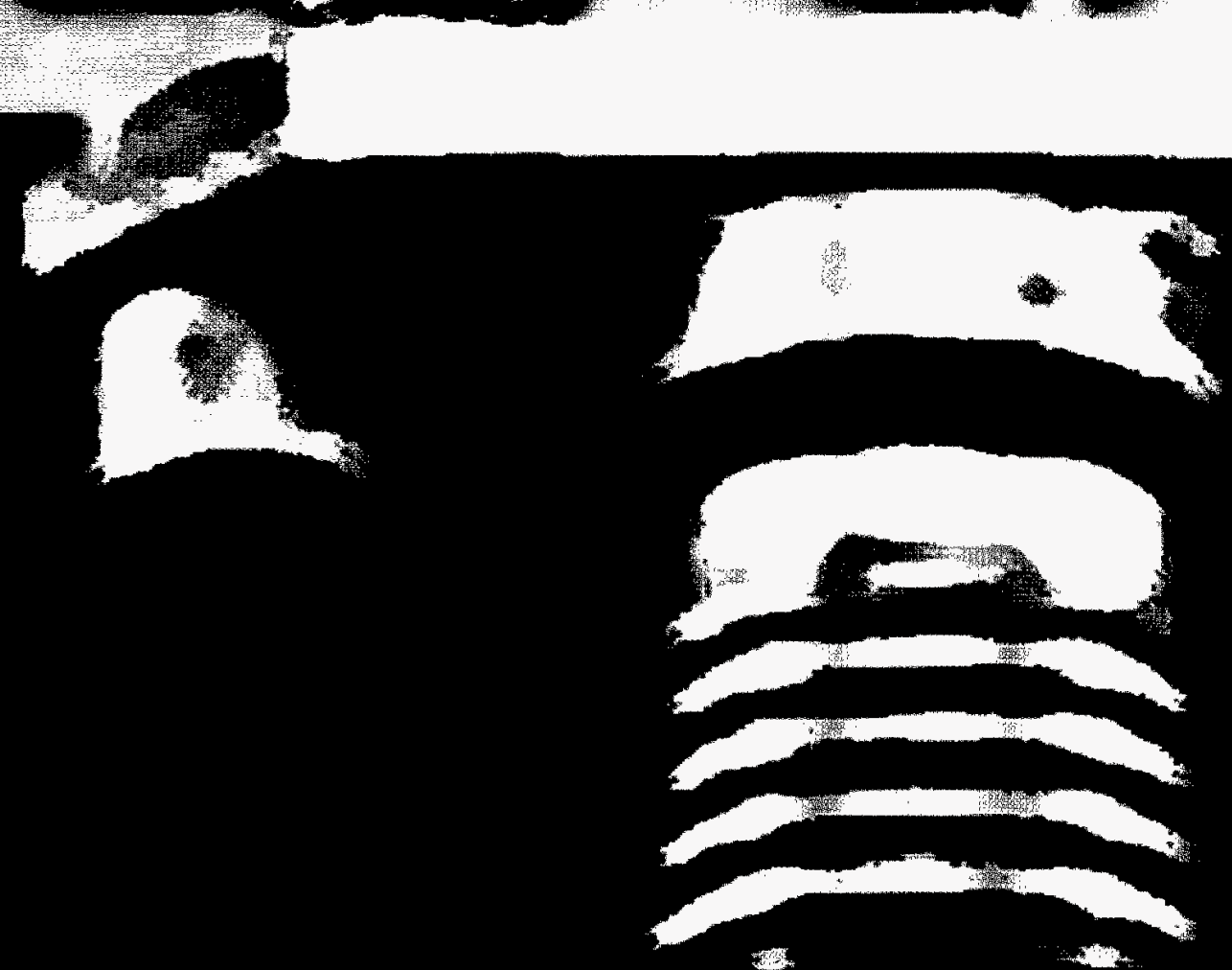

tro
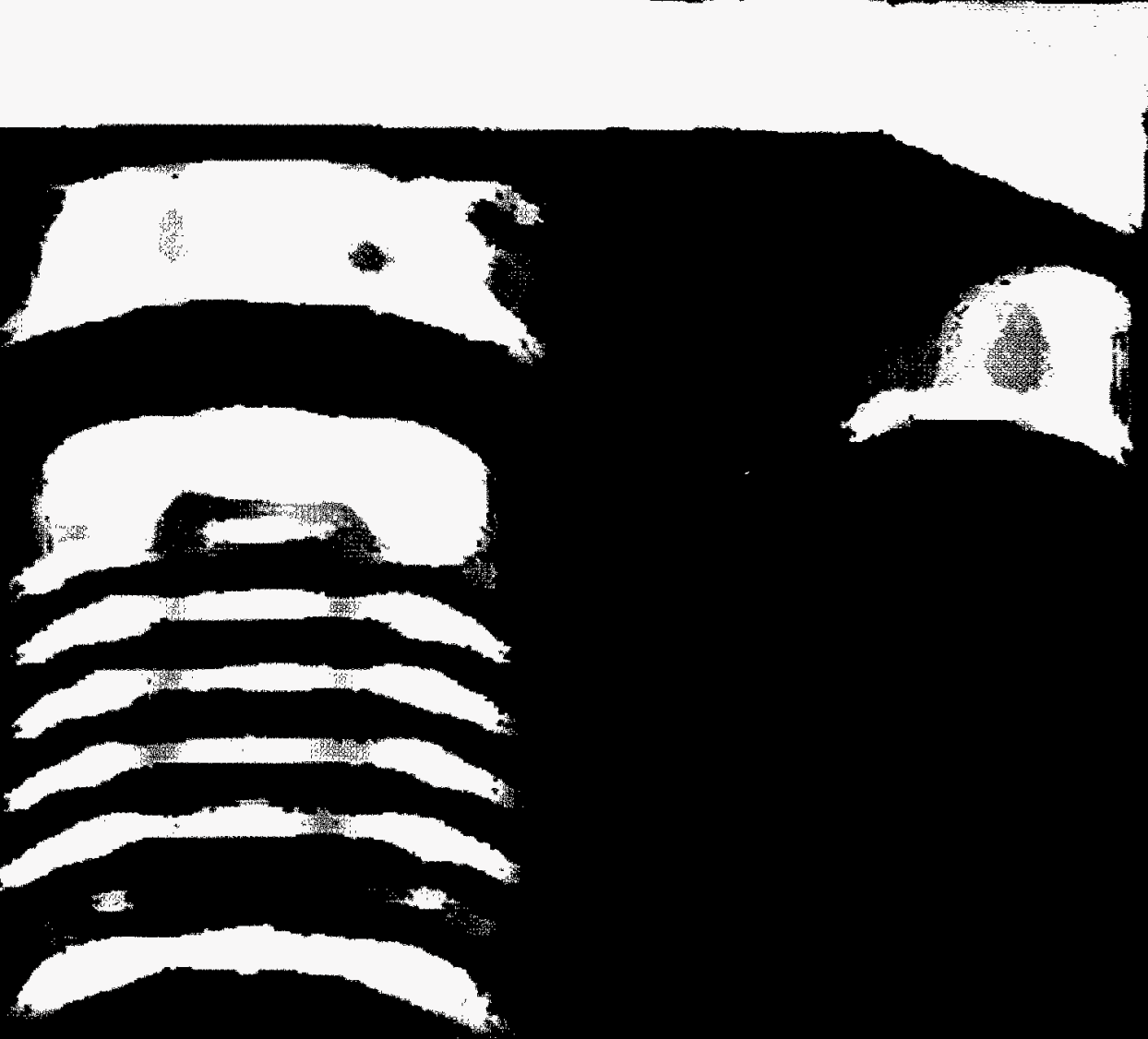


\section{INVESTINO FOR THE FUTURE}

\section{ivermore will maintain its \\ Lvitality by anticipating and}

\section{changing to meet evolving}

\section{national needs.}

This tiny optical amplifier, winner of a 1996 R\&D 100 Award, is a candidate for use in many areas, including network communication, cable TV distribution, and computer interconnections.
A vibrant laboratory has strong programsprograms that are both technically challenging and important. We will work with sponsors to anticipate the future needs of the nation, keep them appraised of emerging technical opportunities, and identify those areas where science and technology can enhance security and national well-being. To succeed, we must continue to be an integral and active part of the nation's science and technology infrastructure, participating in the national dialogue on important science issues and broadly recognized as a scientific leader. We also must continue to make internal investments that develop the skills and capabilities needed to meet customers' needs and seize opportunities to benefit the nation.

\section{ENGAGING SPONSORS AND THE TECHNICAL COMMUNITY}

We will engage in effective dialogue with sponsors to understand their needs, and we will interact with the broader technical community to understand future opportunities.

- Understanding Sponsors' Needs. By participating in the program planning and strategic planning activities of our sponsors, we will provide technical input and gain insights to better align Laboratory program planning with their vision and goals. In addition, Livermore employees will be encouraged to take temporary or rotational assignments at federal offices, departments, and agencies to provide direct technical input and foster effective communication between Washington and the Laboratory.

- Technical Resource to the Government. Livermore will continue to serve as a technical resource for the federal government to use in the development of effective public policy. In particular, with support from Livermore and its other national laboratories, the Department of Energy is uniquely capable of assessing the potential impacts of policy actions and providing technical assessments of policy choices related to energy security, nuclear threat reduction and arms control, and environmental quality. Livermore is also a technical resource for the State of California.

- Outside-the-Laboratory Review. The Laboratory benefits greatly from the reviews by the University of California's President's Council on the National Laboratories, which oversees the work performed at the Livermore, Lawrence Berkeley, and Los Alamos national laboratories. We will continue to use external review committees to assess the quality of Livermore's activities, help prioritize research opportunities, exchange information, and facilitate new collaborative relationships.

- Professional Interactions. Livermore staff members participate in professional organizations and external advisory committees, which are a source of ideas to shape future programs. Working closely with key professional societies will help us stay at technology's leading edge. The interactionsowill also provide Livermore scientists and engineers with opportunities to demonstrate leadership in their disciplines and help in recruiting and retaining key personnel.

- Opening Up the Laboratory. Our goal is to make the Laboratory more accessible to facility users, partners, and customers. Implementation of Livermore's site reconfiguration plans will make it easier for visitors to work with Laboratory colleagues, providing opportunities for infusion of new ideas and approaches in research projects. 
- Improved Communication of Information. The Laboratory will make use of rapid advances in communications technology to effectively disseminate technical information to the research community and leaders in the federal government. We are becoming more accessible through open information networks. We are also improving Laboratory communications with the general public and regional audiences. We are using the Internet for institutional publications, which have been redesigned to be useful to a broader audience. We will be highly responsive to information requests and provide more focused material about major Laboratory programs.

\section{FOCUSING LABORATORY INVESTMENTS}

The present strengths of Livermore are, in large part, a product of investment choices in the past. To ensure continuing strong programs, we are improving the management of internal investments at the Laboratory so that they are more sharply focused on maintaining institutional vitality and creating capabilities to meet future national needs. Livermore's investments are in three areas: developing future programs, strengthening the scientific and technical base, and maintaining the institutional infrastructure. Funds for these investments come from the Laboratory Directed Research and Development (LDRD) tax and loads levied to operate facilities and support the overhead functions of the Laboratory. As overhead costs continue to be reduced, we will be able to reduce or reallocate the internal loads levied to support overhead functions and facilities. We will continue to clarify all sources of cost at the Laboratory so that program managers can make the best investment decisions. Clarity in understanding costs will also help Laboratory management levy loads in an equitable manner and stimulate effective cross-organizational programs and initiatives.

- Guidance for Investment Decisions. Internal investment decisions will be guided by five strategic councils at the Laboratory, which are focused on national security, energy and environmental sciences, biosciences, science and technology, and operations. Created in 1996, the councils provide guidance for LDRD proposals and participate in the review process to the ensure the relevancy of LDRD projects to Laboratory missions. The councils are assisting in the development of new approaches to assess the quality of science and technology at the Laboratory. These quality assessments will be used to guide investment decisions.

- Weapons-Supporting Research. We have changed the way we pursue mid- to long-term science and technology development to support weapons program activities. Now national security program managers at the Laboratory assume greater responsibility for balancing resources each year between direct program support and support for their relevant science and technology base.

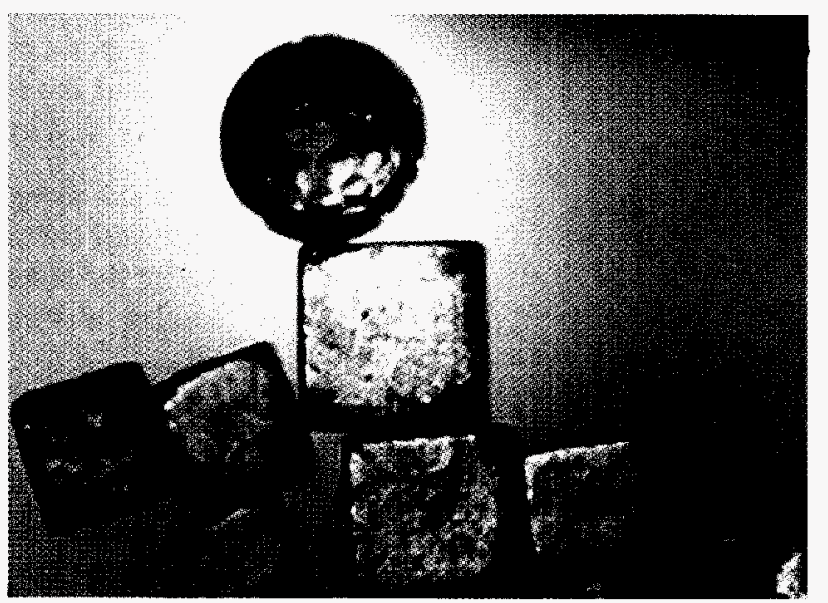

A target capsule for the National Ignition Facility is shown here above grains of table salt. 
Our commitment is to anticipate and meet

the nation's needs

through the pursuit of innovative science and technology at a great laboratory.
- Laboratory-Directed Research and Development (LDRD). Congress established LDRD as a means for the Department of Energy laboratories to directly fund creative, innovative, basic, and applied research activities in areas not immediately supported by sponsors. We fund LDRD at the allowed annual level of $6 \%$. At Livermore, LDRD supports research and development projects that will enhance the Laboratory's core strengths, nurture research efforts that expand the Laboratory's scientific and technical horizons, and create important new capabilities so that the Laboratory can respond promptly and effectively to new missions and national priorities. Most of the LDRD investment goes to either Strategic Initiatives (major multiyear projects) or Exploratory Research (also aligned with the

Laboratory's strategic direction and long-term vision, but only involving one to three researchers). Proposals are reviewed by committees of peers, and the Director has final approval. To ensure the program's quality, an external advisory committee reviews the LDRD program periodically.

- Long-Range Planning. The planning perspective as presented in this document is three to five years. We will form a long-range planning group to explore on an institution-wide basis the 10- to 25 -year technical and programmatic landscape and opportunities for future activities at Livermore.

\section{CREATING THE NATION'S FUTURE}

In Creating the Laboratory's Future, we summarize Livermore's strengths and the direction of programs and initiatives that will contribute to creating the nation's future. Our commitment is to anticipate and meet the nation's needs through the pursuit of innovative science and technology at a great national laboratory.

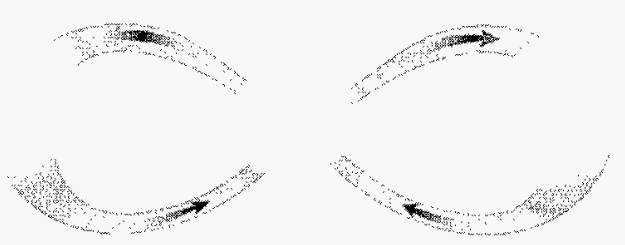

Visualization of core sample data (left) is one step in developing a 3D simulation (right) for treating groundwater contamination of the Livermore site.
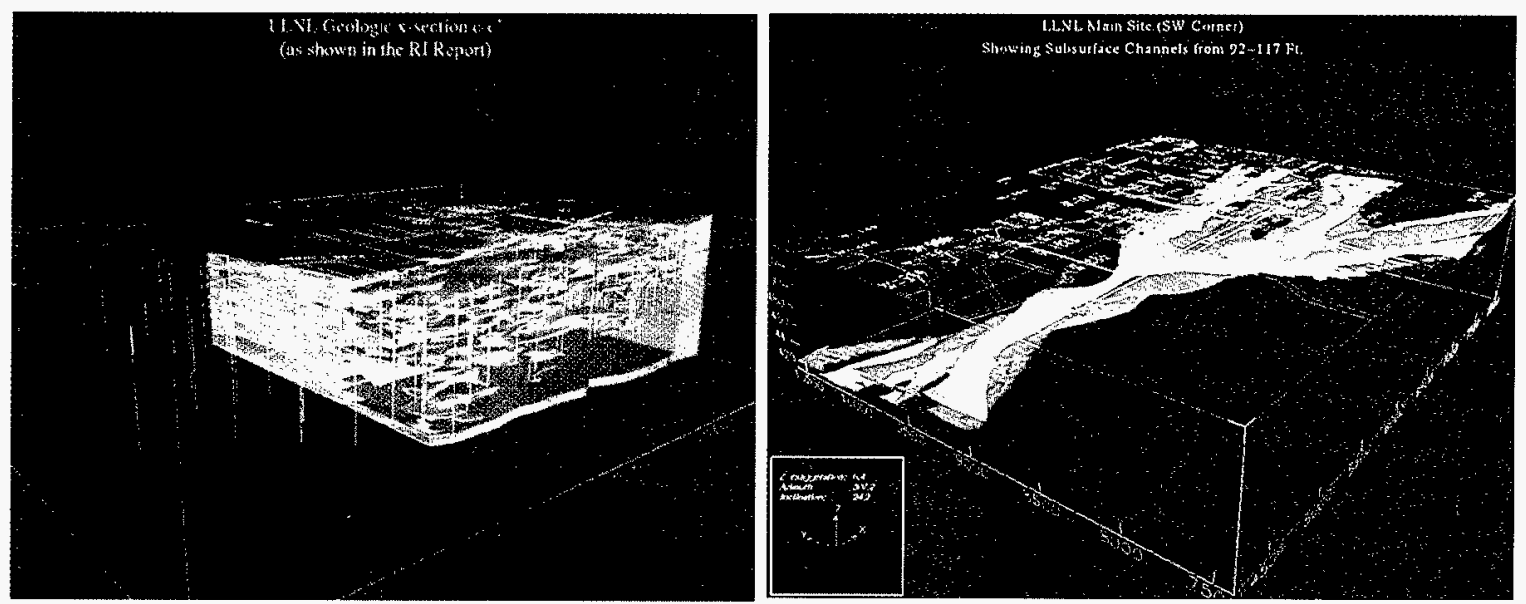


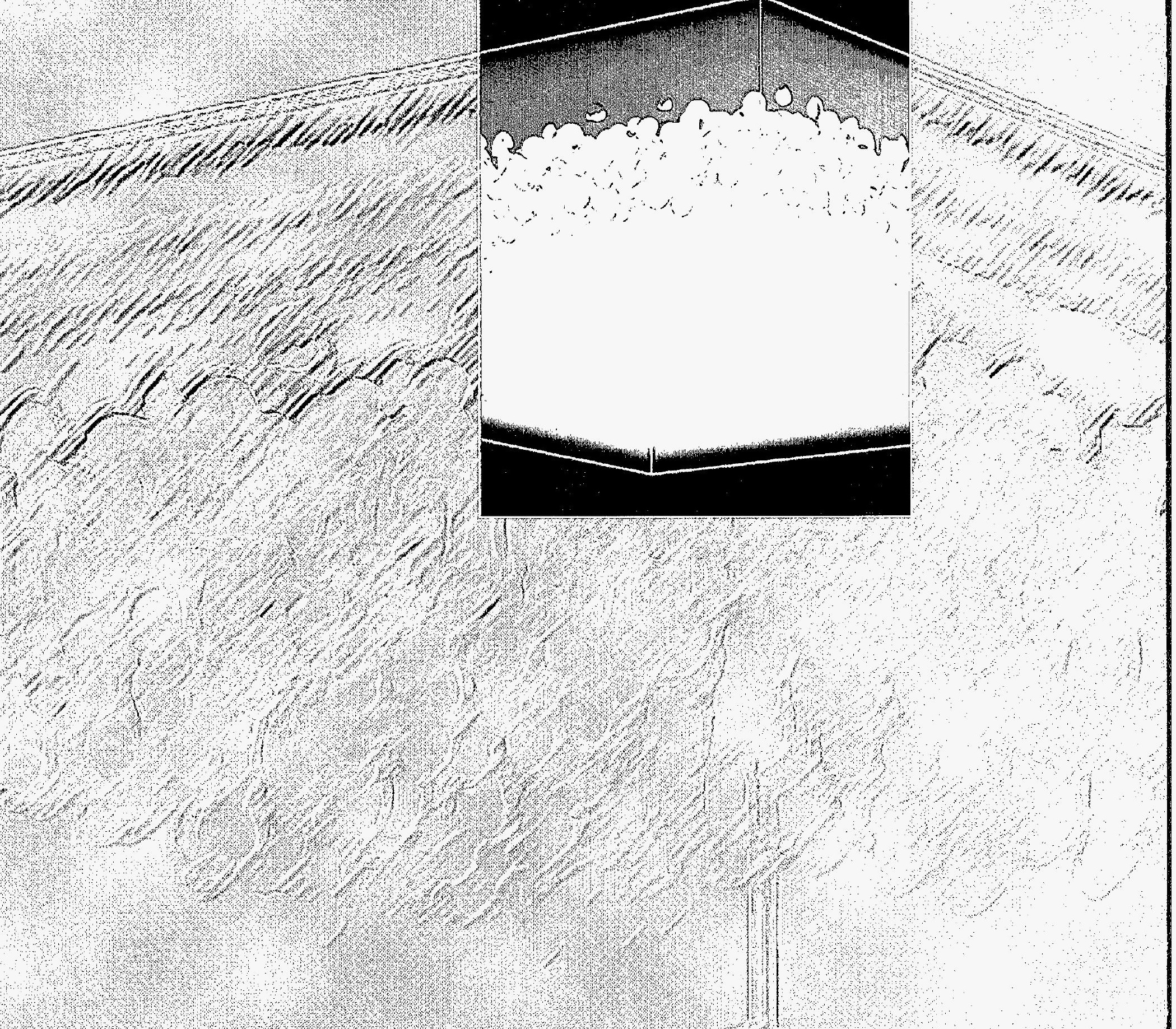

This document was prepared as an account of work sponsored by anagency of the United States Government. Neither the United States Government nor the University of Calfornia nor any of thet employ ees makes any warranty, expressed or inplied or assumes any legal thabifit, or fesponsibility for the accuracy, completeness, or usefulness of any information apparatios product, or process disclo sed, or represents that its use would not infringe prixately owned ights Reference herein to any spedfic commercial product, process, or service by trade name, trademarh, manufacture, or otherwise, does not necessarily constitute or imply lts endorsement, recommendation or favoring by the United states Government or the University of California. The views and opinions of authors expressed herein do not necessarily state or reflect those of the United states Government or the University of Calfornia and shall not be used for advertising or praduct endorsement purposes.

Wofl pefolf bed under the auspices of the $U S$ Department of Energy by Lawrence Livermore National babaratory ind 5 of 


\section{CORE VALUES}

$T_{t a t}$ provide the scientific and technological excellence needed to meet critical national missions, the

\section{Laboratory staff}

\section{is guided by the}

\section{highest}

principles:

\section{INTEGRITY}

We will continuously earn and uphold the public trust, by

- Maintaining the highest ethical standards in science and technology.

- Supporting a culture of academic freedom.

- Demonstrating personal and institutional responsibility in Laboratory operations.

- Assuring honest, open interactions with all customers and team members-within the Laboratory, in the communities we serve, and with our partners.

\section{COMMITMENT}

As a national laboratory, we will help meet the nation's science and technology needs, by

- Focusing the Laboratory's science and technology on national objectives.

- Meeting the goals and requirements of customers.

- Continuously improving productivity and efficiency.

\section{EXCELLENCE}

To solve the nation's most challenging technical problems, we will provide the best science, engineering, management, and people, by

- Discovering and implementing creative, innovative, effective solutions to complex problems.

- Attracting and encouraging the best available talent.

- Valuing the diversity and creativity of our workforce.

- Motivating and rewarding employee excellence.

- Managing business, safety, and environmental protection to achieve a high level of accountability in an atmosphere of continuous improvement.
Turbulent mixing of fluids is shown in an image from high-resolution 3D hydrodynamic calculations on a new supercomputer that is part of the Accelerated Strategic Computing Initiative. 


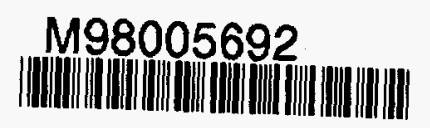

Report Number (14) LICRL-AR- - 128 C 45

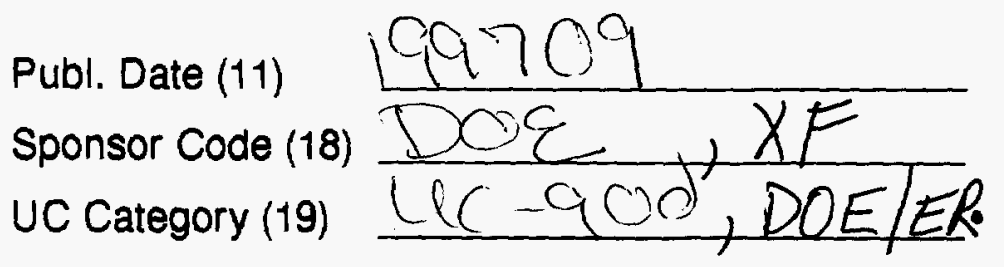

19980702052 